Article

\title{
Non-Parametric Statistical Approaches for Leaf Area Index Estimation from Sentinel-2 Data: A Multi-Crop Assessment
}

\author{
Margherita De Peppo ${ }^{1, *}$, Andrea Taramelli ${ }^{2,3}{ }^{\circledR}$, Mirco Boschetti ${ }^{4}\left({ }^{\oplus}\right.$, Alberto Mantino ${ }^{1}{ }^{\circledR}$, Iride Volpi ${ }^{1}{ }^{\circledR}$, \\ Federico Filipponi ${ }^{2}{ }^{-}$, Antonella Tornato ${ }^{2}{ }^{-}$, Emiliana Valentini ${ }^{2,5}$ and Giorgio Ragaglini ${ }^{6}$ \\ 1 Sant' Anna School of Advanced Studies, Institute of Life Sciences, Piazza Martiri della Libertà 33, \\ 56127 Pisa, Italy; a.mantino@santannapisa.it (A.M.); i.volpi@santannapisa.it (I.V.) \\ 2 Institute for Environmental Protection and Research (ISPRA), via Vitaliano Brancati 48, 00144 Rome, Italy; \\ andrea.taramelli@iusspavia.it (A.T.); federico.filipponi@isprambiente.it (F.F.); \\ antonella.tornato@isprambiente.it (A.T.); emiliana.valentini@cnr.it (E.V.) \\ 3 Institute for Advanced Study of Pavia (IUSS), Palazzo del Broletto, Piazza della Vittoria 15, 27100 Pavia, Italy \\ 4 Institute for Electromagnetic Sensing of the Environment, Italian National Research Council, Via Bassini 15, \\ 20133 Milan, Italy; boschetti.m@irea.cnr.it \\ 5 Institute of Polar Sciences, Italian National Research Council, via Salaria km 29,300, 00015 Rome, Italy \\ 6 Dipartimento di Scienze Agrarie e Ambientali-Produzione, Territorio, Agroenergia, \\ Università degli Studi di Milano, Via Celoria 2, 20133 Milano, Italy; giorgio.ragaglini@unimi.it \\ * Correspondence: m.depeppo@santannapisa.it
}

\section{check for} updates

Citation: De Peppo, M.; Taramelli, A.; Boschetti, M.; Mantino, A.; Volpi,

I.; Filipponi, F.; Tornato, A.; Valentini,

E.; Ragaglini, G. Non-Parametric

Statistical Approaches for Leaf Area Index Estimation from Sentinel-2 Data: A Multi-Crop Assessment. Remote Sens. 2021, 13, 2841. https://doi.org/10.3390/rs13142841

Academic Editor:

Zbyněk Malenovský

Received: 29 April 2021

Accepted: 18 July 2021

Published: 20 July 2021

Publisher's Note: MDPI stays neutral with regard to jurisdictional claims in published maps and institutional affiliations.

Copyright: (c) 2021 by the authors Licensee MDPI, Basel, Switzerland. This article is an open access article distributed under the terms and conditions of the Creative Commons Attribution (CC BY) license (https:// creativecommons.org/licenses/by/ $4.0 /)$.
Abstract: The leaf area index (LAI) is a key biophysical variable for agroecosystem monitoring, as well as a relevant state variable in crop modelling. For this reason, temporal and spatial determination of LAI are required to improve the understanding of several land surface processes related to vegetation dynamics and crop growth. Despite the large number of retrieved LAI products and the efforts to develop new and updated algorithms for LAI estimation, the available products are not yet capable of capturing site-specific variability, as requested in many agricultural applications. The objective of this study was to evaluate the potential of non-parametric approaches for multi-temporal LAI retrieval by Sentinel-2 multispectral data, in comparison with a VI-based parametric approach. For this purpose, we built a large database combining a multispectral satellite data set and ground LAI measurements collected over two growing seasons (2018 and 2019), including three crops (i.e., winter wheat, maize, and alfalfa) characterized by different growing cycles and canopy structures, and considering different agronomic conditions (i.e., at three farms in three different sites). The accuracy of parametric and non-parametric methods for LAI estimation was assessed by cross-validation (CV) at both the pixel and field levels over mixed-crop (MC) and crop-specific (CS) data sets. Overall, the non-parametric approach showed a higher accuracy of prediction at pixel level than parametric methods, and it was also observed that Gaussian Process Regression (GPR) did not provide any significant difference ( $p$-value $>0.05$ ) between the predicted values of LAI in the MC and CS data sets, regardless of the crop. Indeed, GPR at the field level showed a cross-validated coefficient of determination $\left(\mathrm{R}^{2} \mathrm{CV}\right)$ higher than 0.80 for all three crops.

Keywords: LAI; Sentinel-2; wheat; maize; alfalfa; parametric; non-parametric; GPR

\section{Introduction}

With the global increase in food demand, obtaining timely information regarding crop growth and retrieving detailed data of crop health have become essential aspects for developing strategic food policies and ensuring sustainable agroecosystem management. Reliable monitoring of crop yields at the regional scale can support policy makers in quantifying food supply (GEOGLAM initiative, https:/ / www.earthobservations.org/geoglam.php, accessed on 20 April 2021), while mapping crop conditions at a field scale can assist farmers in agroecosystem management [1]. The leaf area index (LAI), defined as the total one-sided 
area of leaf tissue per unit ground, is a biophysical indicator used to represent the dimension of the crop canopy and its variation over time [2]. Indeed, LAI measurements have been widely adopted for crop monitoring, as well as for modelling applications [3-5], being a key state variable associated with processes including light interception and soil-crop water balance [6-8]. Moreover, at the landscape level, LAI maps can provide information on cropping system status, according to crop rotation, soil coverage, crop phenological development, and their response to management and anomalies caused by extreme events in time (across seasons) and space (among and within fields) [4,9].

Remote sensing (RS) provides an effective way to retrieve LAI values at different spatial and temporal scales, as has been successfully demonstrated in different contexts [10-12]. According to Verrelst et al. [13], the approaches for biophysical parameter retrieval (e.g., LAI) can be classified in four main categories: (i) parametric regression methods, which assume an explicit relationship between spectral data (e.g., Vegetation Indices) and biophysical data (e.g., LAI); (ii) non-parametric regression methods, which do not require an explicit relationship and data distribution; (iii) physical-based methods, using radiative transfer models (RTMs) to simulate the interaction between spectral radiation and vegetation biophysical and biochemical parameters; and (iv) hybrid retrieval methods, combining non-parametric and physical-based approaches.

The first category relies on regression analyses (ground-LAI vs. VI) and their easy implementation for operational vegetation cover monitoring applications [13]. However, the drawbacks of VI-based methods are related to the implicit assumption that the reflectance variability depends only (or mainly) on the LAI [14]. Instead, canopy reflectance is strongly affected by several factors, such as the aboveground biomass, chlorophyll content, canopy architecture, and soil background, which vary in space and time, according to the crop phenology and seasonal conditions $[15,16]$. Therefore, parametric approaches are often crop- and site-specific, due to their dependence on the regression data set, thus making them inadequate for the general purpose of retrieving LAI values from a diversified landscape mosaic [17]. In this context, several VI formulations, according to different band compositions, have been developed, in order to cope with these limitations and to be better suited to mixed-crop scenarios [18-21]. For example, previous research has shown the potential of VIs based on red-edge (RE) and short-wave infrared regions (SWIR), in terms of being less sensitive to specific crop types than traditional Red/NIR-based indices (e.g., NDVI) [19,22-24]. Nevertheless, further investigations into the accuracy of parametric methods based on RE and SWIR vegetation indices are needed, in order to assess their accuracy for satellite remote sensing.

The second category refers to machine learning regression algorithms (MLRAs). MLRAs have gained widespread popularity, as they address the limitations of VI-based methods [24]. For this reason, different studies interested in LAI estimation have compared the performance of different MLRAs, and showed that the Gaussian processes regression (GPR), bagging trees (BAGTREE), and boosting trees (BOOST) are robust algorithms for LAI retrieval $[13,25,26]$. However, a drawback of MLRA methods is their instability when applied to data sets deviating from the training data set [25]. Therefore, additional investigation of such algorithms trained over a data set for crop-specific and mixed-crop estimation is required.

The third category includes the RTMs for the simulation of canopy light interception processes. Several authors have suggested the use of such complex models to exploit the full spectrum acquired with the RS sensors. Nevertheless, RTM calibration requires several input parameters, where the potential lack of these inputs could induce several uncertainties compromising the estimation accuracy [13].

Numerous LAI products have been developed, according to these different methodological approaches [14]. Gonsamo and Chen [27] used the MODIS/MISR sensor, with a parametric approach (LAI-VIs relationship), to obtained a global LAI at $250 \mathrm{~m}$ spatial resolution and 10 days temporal resolution. Yan et al. [28] used SNPP/VIIRS data retrieved a global LAI product at 8 days of temporal resolution and $500 \mathrm{~m}$ of spatial resolution by 
RTM. Moreover, García-Haro et al. [29] used an AVHRR sensor to obtain an operational LAI product at $1.1 \mathrm{~km}$ of spatial resolution and 10 days of temporal resolution using GPR. Baret et al. [30] used a SPOT/VEGETATION sensor and, based on a hybrid non-parametric approach (Neural Network and GPR), retrieved a global LAI with 10 days of temporal resolution and $1.5 \mathrm{~km}$ of spatial resolution. Despite the large number of retrieved LAI products and the efforts to develop new and updated algorithms for LAI estimation, the available products are not yet capable of capturing the site-specific variability required in many agricultural applications, Therefore, specific LAI data sets with higher spatial and temporal consistency are required. To cope with the spatial and temporal variability of heterogeneous agricultural systems, high spatial resolution satellite systems (10-30 m), such as Sentinel-2, have been gathering growing interest in the field of agronomic research $[24,26]$. Thus, studies devoted to improving the accuracy and spatial resolution of LAI estimation are needed, in order to respond to the increasing demand for tools to support the site-specific management of crops and landscape [31]. Therefore, this study was focused on the robustness of non-parametric approaches in relation to different sources of variability such as crop species-, growth stage-, farm-, and year-specific conditions, in order to capture site-specific variability.

The objectives of this study were: (i) to evaluate the potential of non-parametric algorithms at pixel level (within field) and at field level for multi-crop and multi-temporal LAI retrieval; and (ii) to test the temporal consistency of the retrieved LAI at field level for crop monitoring over the entire growing season. Thus, to achieve these objectives, we performed an intensive field campaign, contemporary to S2 data acquisition, to collect ground-LAI measurements collected in Tuscany (Central Italy) over two growing seasons (2018 and 2019), including three crops (i.e., winter wheat, maize, and alfalfa), characterized by different growing periods and canopy structures, and considering different agronomic conditions (i.e., three farms in three different sites). Indeed, the final database (ground-LAI and S2 spectral data) is a potential contribution for other studies, thanks to the spatialspectral-temporal characteristics of LAI data.

\section{Materials and Methods}

The methodology followed for the assessment of the performances of parametric and non-parametric approaches consisted of four steps: (i) data collection and pre-processing (Section 2.2); (ii) model definition parametric and non-parametric LAI retrieval (Section 2.3); (iii) accuracy assessment (Section 2.4); and (iv) temporal consistency analysis of LAI retrieval (Section 2.5). Concerning MLRAs, further analysis was performed, in order to evaluate the selection of bands in the retrieval process (Section 2.3.2.1). Indeed, the strength of MLRAs, with respect to regression based on Vis, involves the exploitation of the full spectral information of optical data. The spectral band contribution is important to assess such a contribution and to interpret the model results. The flowchart is presented in Figure 1.

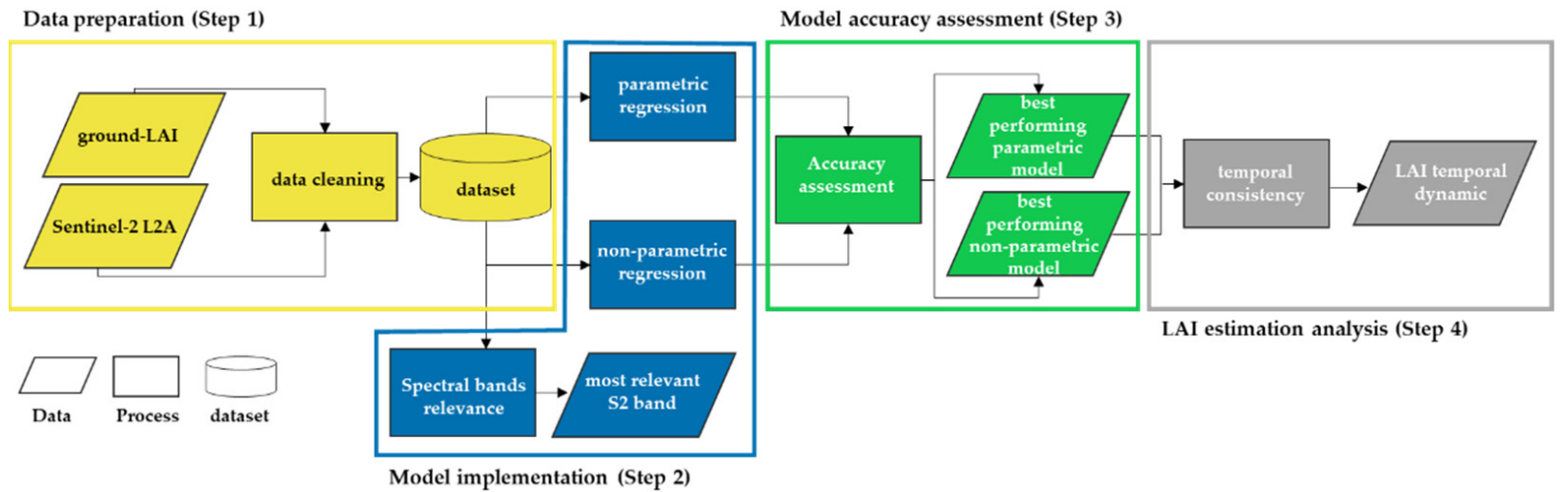

Figure 1. General framework of the work: Step 1 (Yellow boxes) data preparation; Step 2 (Blue boxes) model implementation; Step 3 (Green boxes) model accuracy assessment; and Step 4 (Grey boxes) LAI estimation analysis. 


\subsection{Study Area}

The study area is located $10 \mathrm{~km}$ from Pisa, Tuscany, Central Italy (Figure 2a). The area is flat and the climate is Mediterranean, with a mean annual precipitation of $907 \mathrm{~mm}$ and a mean annual temperature of $15{ }^{\circ} \mathrm{C}$ (long-term average 1986-2016). According to land-cover spatial information of the Tuscany regional authorities (http:/ / dati.toscana.it/, accessed on 20 April 2021), in 2017-2019, the three prevalent arable crop categories were: (i) cool-season cereals; (ii) perennial meadows; and (iii) warm-season cereals. In order to cope with the main categories of the area, the following crops were considered in this study: $\mathrm{C} 1$-winter wheat (Triticum aestivum L.); C2-maize (Zea mays L.); and C3-alfalfa (Medicago sativa L.). The three crops were monitored along their growing seasons at three different test sites. The three sites were located in three different Farms (F): F1 (San Piero), F2 (Coltano), and F3 (Madonna dell'Acqua), having an extension of the considered fields of about 25, 42, and 36 hectares, respectively (Figure $2 b$ ).

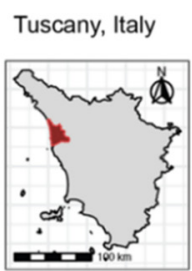

(a) Study area, Pisa, Tuscany

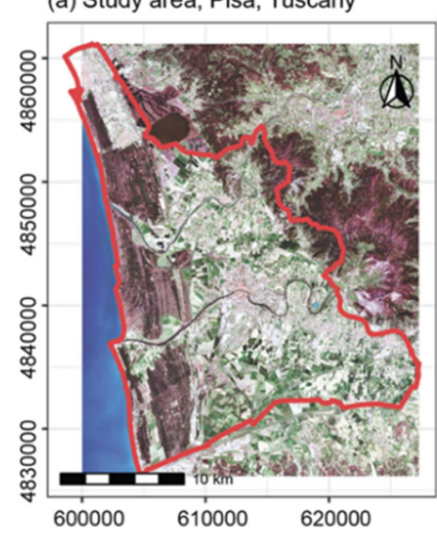

(b) Farms and crops of the study area

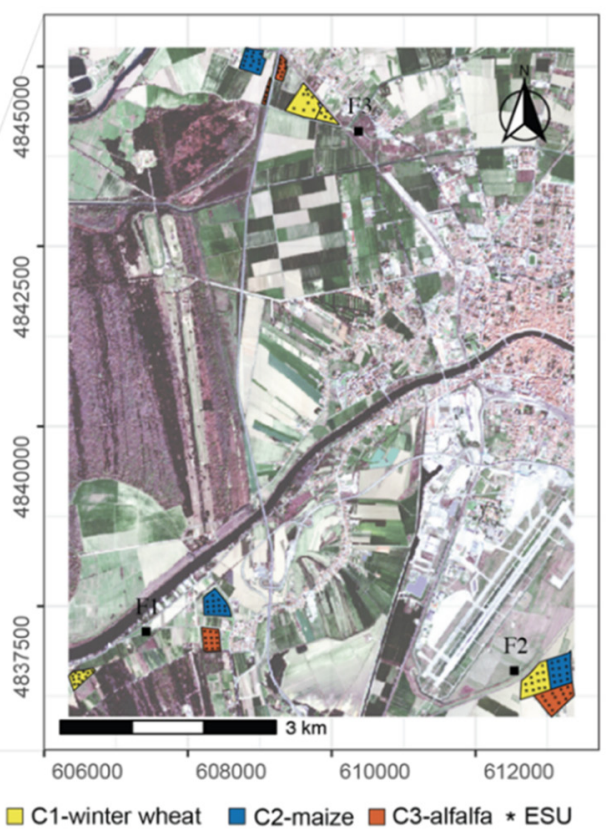

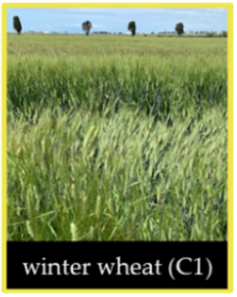
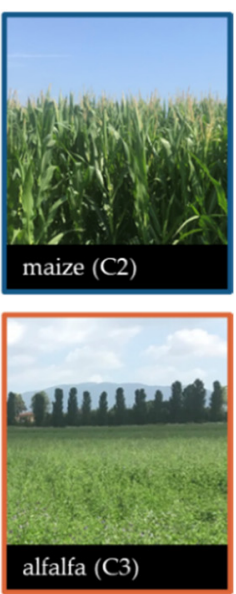

Figure 2. (a) Study area in Tuscany, Italy; (b) farms and crops of the study area (C1-winter wheat, C2-maize, and C3-alfalfa) in the three farms (F1-San Piero, F2-Coltano, and F3-Madonna dell'Acqua) in Pisa, Italy.

\subsection{Data}

\subsubsection{In Situ Measurements}

At each site, ground-LAI measurements were collected using the Validation of Land European Remote Sensing Instruments (VALERI) sampling strategy [32,33]. VALERI is based on an Elementary Sampling Units (ESU) upscaling approach, in order to capture the variability between the investigated fields and within the field of each crop, while including the variability within a theoretical pixel [33]. The corresponding scale of ESU is a high spatial resolution pixel of S2, and ESU is defined as a plot of $20 \mathrm{~m} \times 20 \mathrm{~m}$, where an investigated area of $1 \mathrm{~m}^{2}$ was selected. The ground-LAI measurements were conducted from March 2018 to October 2019. In particular, in the 2018 field campaign, measurements were carried out monthly and in each farm; while, in the 2019 field campaign, weekly measurements were carried out only in F3. On each sampling date, for each field, we collected 12 ESU; where, within each ESU, four (2018) and one (2019) replicate measurements of ground-LAI were sampled. Subsequently, in order to obtain a unique representative value for ESU, the ground-LAI mean was calculated within each ESU. A 
total of 598 measured ESUs were obtained over the study area. Ground-LAI measurements were performed using SunScan (Delta-T Devices, Cambridge, UK), assuming a random distribution of the foliage (effective ground-LAI) under clear-sky conditions. Moreover, to include bare soil conditions [34], 96 bare soil (LAI = 0.0) ESUs were included in the groundLAI database (12 for each field, during the germination stage of winter wheat and maize for each sampling year). Therefore, we obtained a database consisting of 694 observations.

By means of phenological observations and expert knowledge, we conducted a preliminary screening of ground-LAI anomalies, in order to exclude sampling disturbances arising out of instrument calibration. Moreover, Grubbs' test was performed on groundLAI measurements data, in order to identify and flag outliers [35]. Both screenings were conducted per field per date, in order to avoid possible sources of disturbance on the day of sampling. Grubbs' test was performed with the "outliers" library in the R environment [36]. After the screenings, a total of 558 representative ESUs were maintained, while 232 ESUs were excluded from the measured ground-LAI database (Table 1).

Table 1. Number of ESUs sampled in the three farms (F1, F2, and F3) during the 2018 and 2019 field campaigns for the three crops $(\mathrm{C} 1=$ winter wheat; $\mathrm{C} 2=$ maize; $\mathrm{C} 3=$ alfalfa $)$.

\begin{tabular}{cccc}
\hline $\begin{array}{c}\text { Year of Sampling } \\
\text { Campaign }\end{array}$ & Farm & Crop & ESU \\
\hline & F1 & C1 & 55 \\
& & C2 & 48 \\
& & C3 & 48 \\
& F2 & C1 & 33 \\
& & C2 & 36 \\
& F3 & C3 & 25 \\
& & C1 & 26 \\
& & C2 & 48 \\
2019 & F3 & C1 & 31 \\
\hline Total & & C2 & 56 \\
& & & 72 \\
\hline
\end{tabular}

Beside LAI measurements, the phenological stages of the crops were recorded during each sampling date, based on the Biologische Bundesanstalt, Bundessortenamt, and Chemical Industry scale (BBCH), a German scale used to identify the phenological development stages of a plant [37]. Data of crop phenology were arranged, in order to refer LAI measurements to the main crop development stages. Thus, for winter wheat and maize, four main stages were identified: GE, from germination to full emergence; SE, from early leaf development to complete stem elongation; $\mathrm{Fl}$, from initial stages of flower differentiation to end of anthesis; and FD, from initial stages of fruit development to complete fruit maturity. Conversely, in alfalfa, only two stages were considered: $\mathrm{Vg}$, the vegetative stage, occurring after cut or overwintering; and Fl, from initial stages of flowering to mowing.

\subsubsection{Sentinel-2 Data}

Copernicus Sentinel-2 (S2) is a satellite mission carrying the MSI multispectral sensor, which is characterised by high spatial resolution $(10 \mathrm{~m}, 20 \mathrm{~m}$, and $60 \mathrm{~m})$, high revisit capability (5 days with two satellites), and a moderately large band set (13 spectral bands) from the visible to short-wave infrared (Table A1) [38,39]. The S2 Level 2A (L2A) images were downloaded from the Theia Land Data Centre, which provides time-series of topcanopy surface reflectance which is orthorectified, terrain-flattened, and atmospherically corrected using the MACCS-ATCOR Joint Algorithm (MAJA) [40]. A total of 37 cloud-free images, collected in correspondence with the in situ monitoring period, were used to analyze the relationship between measured ground-LAI and S2 data. Moreover, the most 
commonly-used S2 bands for vegetation studies at $10 \mathrm{~m}$ (B02, B03, B04, and B08) and $20 \mathrm{~m}$ (B05, B06, B07, B08A, B11, and B12) were selected for the analysis (Table A1) [31]. Then, the $10 \mathrm{~m}$ spatial resolution bands were resampled to $20 \mathrm{~m}$ spatial resolution.

In order to couple the ground-LAI values and the S2 spectral information, the centroid of each ESU was used to extract zonal statistics of S2 time-series using the R software package "raster" [36,41]. S2 reflectance data values within \pm 5 days from ground data collection were associated to ground-LAI values. The association of ground-LAI values with the corresponding S2 data was carried out using the SQL database software PostgreSQL 9.5, by joining the two data sets. As a result, a complete SQL database, consisting of 558 records of coupled ground-LAI and S2 data, was obtained for the three crops of each farm in the reference period (October 2017 to October 2019; Figure A1 (Appendix A)).

\subsection{LAI Retrieval Approaches}

\subsubsection{Parametric Methods}

By means of a parametric approach, the empirical relationship between vegetation indices (VIs) and ground-LAI was analyzed, including different sources of variability (crop type, farm conditions, and crop growth). The VIs given in Table 2 were selected, based on previous studies which evaluated visible, red edge, and shortwave infrared as the most effective wavelengths for LAI estimation over different crop types [34,42].

Table 2. Vegetation Indices (VIs).

\begin{tabular}{cccc}
\hline VIs & Name & Formula & References \\
\hline NDVI & Normalized difference vegetation index & $(\mathrm{B} 08-\mathrm{B} 04) /(\mathrm{B} 08+\mathrm{B} 04)$ & {$[43]$} \\
SeLI & Simple Sentinel-2 LAI Index & $(\mathrm{B} 8 \mathrm{~A}-\mathrm{B} 05) /(\mathrm{B} 08 \mathrm{~A}+\mathrm{B} 05)$ & {$[34]$} \\
NBR & Normalized Burn Ratio & $(\mathrm{B} 08-\mathrm{B} 12) /(\mathrm{B} 08+\mathrm{B} 12)$ & {$[44]$} \\
\hline
\end{tabular}

Linear and non-linear functions were used for LAI prediction. The linear model (LM) was selected, according to a previous study which demonstrated the good performance of LM for LAI prediction in a mixed-crop scenario [34]. The non-linear model was selected, considering the results of previous studies evaluating the relationship between the groundLAI and VIs [42,45]. Specifically, the dose-response three-parameter logistic model was selected, in order to evaluate the logistic relationship between ground-LAI and VIs [21]. For the linear model (LM), we adopted the general function of Equation (1) and its inverse (Equation (2)), where $a$ is the intercept and $b$ is the slope:

$$
\begin{gathered}
\mathrm{VI}=a+\text { bgroundLAI, } \\
\mathrm{LAI}=\frac{(\mathrm{VI}-a)}{b} .
\end{gathered}
$$

The inverse non-linear function $\left(\log _{\mathrm{IF}}\right)$ of the three-parameter logistic model (Equation (3)) was computed based on the parameterization carried out by the doseresponse "drc" $\mathrm{R}$ package [46]. In the equation, $d$ is the curve plateau, which indicates the level at which the VIs saturate; $b$ is the relative slope, which indicates the steepness of the curve; and $e$ is the inflection point, which indicates the point at which the VI value is halfway to its saturation level. Based on Equation (3), the inverse of the three-parameter logistic model was calculated using Equation (4).

$$
\begin{gathered}
\mathrm{VI}=\frac{d}{\{1+\exp [b *(\text { groundLAI }-e)]\}}, \\
\mathrm{LAI}=\ln (d / \mathrm{VI}-1) / b+e .
\end{gathered}
$$

Considering that the domain of the inverse function is VI $\leq d$, the LAI results are unpredictable above the asymptote $d$, as the function is not real. In order to overcome the problem of losing information due to the saturation of VIs, we evaluated the option 
of assigning a default value to pixels with $\mathrm{VI}>d$, which is equal to the maximum value of VI measured below $d$; while, for VI $\leq d$, the pixel value was computed based on the inverse function.

Moreover, to evaluate the robustness of the LM and $\operatorname{LogIF}_{\mathrm{d}}$ over different sources of variability, the functions were parametrized according to the mixed-crop (MC) data set and the crop-specific (CS) subset. Regression analysis was performed using the "drc" package $[47,48]$ in the $\mathrm{R}$ environment [36]. In particular, the general model fitting function dose-response model (drm) was used to fit the regression models and, according to the same parameterization, the inverse functions were calculated.

\subsubsection{Non-Parametric Methods}

The MLRAs were used for multi-crop and multi-temporal LAI estimation by a nonparametric approach. The architecture of these MLRAs and their training processes were based on iterative regression process, and the core of each algorithm is reported in Table 3. More specifically, GPR provides the predictive mean, as well as predictive variance, maximizing the marginal likelihood in the training set, which is learned by hyperparameters through an appropriate kernel function [49]. BAGTREE builds multiple decision trees by iteratively replacing resampled training data and voting for the decision trees, thus leading to a consensus prediction [50]. BOOST incrementally builds an ensemble by training each new instance to emphasize the training instances which were previously mismodelled [51]. Moreover, to evaluate the MLRA performances over different sources of variability, the algorithms were trained over the mixed-crop (MC) and crop-specific (CS) data set collected during the 2018 and 2019 field campaigns. The MLRAs were run by means of the MLRA toolbox [52] of the Automated Radiative Transfer Models Operator (ARTMO) software [53].

Table 3. Machine learning regression algorithms (MLRAs) used in this study.

\begin{tabular}{ccc}
\hline MLRAs & Code & Methods \\
\hline Bagging trees & BAGTREE & Bootstrap method and regression trees \\
Gaussian Process Regression & GPR & Bayesian statistical inference \\
Boosting trees & BOOST & Least squares boosting and regression trees \\
\hline
\end{tabular}

\subsubsection{Spectral Band Relevance}

Crop development stages strongly influence the reflectance information provided by RS sensors. Therefore, information on spectral relevance may be a useful tool for understanding several crop-related reflectance conditions. In this study, the spectral relevance of each S2 band (Section 2.2.2) used for LAI prediction was evaluated, according to the crop type and crop development stage. The GPR models were trained over each growth stage within the crop-specific data sets (CS) and over the crops on the mixed-crop data set (MC). We exploited the property of GPR to evaluate the predictive capacity of each single band by a covariance function, defined as follows:

$$
K\left(x_{i}, x_{j}\right)=\exp \left(-\frac{\left\|x_{i}, x_{j}\right\|^{2}}{2 \sigma^{2}}\right) .
$$

Information of spectral relevance of each $\mathrm{S} 2$ band was obtained by the hyperparameter $\operatorname{sigma}(\sigma)$, which is the weight assigned to the band $(b)$. The $\sigma_{b}$ value was provided by the GPR within the MLRA toolbox implemented in the ARTMO software [52]. The toolbox provides an absolute $\sigma_{b}$ value for each used band. In the supplied hyperparameter, the higher the value of $\sigma_{b}$, the lower the relevance of the band. In this study, in order to obtain a positive representation of the spectral relevance, we converted the lower values of $\sigma_{b}$ into higher ones and calculated the relative $\sigma_{b}$. This is detailed in Equation (6), where $\sigma_{b}$ is the 
spectral relevance, $\max \sigma_{b}$ is the maximum value of $\sigma_{b}$ among the bands used for the GRP training, and sum $\sigma_{b}$ is the sum of $\sigma_{b}$ among the bands used for the GRP training:

$$
\sigma^{2}=\left(1-\left(\sigma^{2} /\left(\max \sigma^{2}\right)\right) /\left(\operatorname{sum} \sigma^{2}\right)\right) * 100
$$

\subsection{Accuracy Assessment}

The accuracy of parametric and non-parametric methods was assessed at pixel and field level using K-fold cross-validation. The K-fold process consists of dividing the data set into $\mathrm{k}$ mutually exclusive groups following a $\mathrm{k}$-fold cross-validation partitioning design [54]. In our case, data were randomly split into $k=3$ subsets of equal size, of which, iteratively, two were used for calibration and one for validation. Using this approach, the dependence on a single random partition into calibration and validation data sets was reduced and all observations were used for both training and validation, with each observation used for validation just one time [55]. The validation at field level was conducted using linear regression between ground-LAI values and predicted LAI, averaged per crop, per field, and per growing stage, while the validation at pixel level was conducted at the ESU scale. The coefficient of determination $\left(\mathrm{R}^{2}\right)$ and root mean square error (RMSE) were calculated to assess the prediction accuracy. The parametric and non-parametric models were selected as those robust and efficient for LAI prediction, considering the average value of RMSE from the cross-validation $\left(\mathrm{RMSE}_{\mathrm{CV}}\right)$ and the average of coefficient of determination estimated between ground-LAI and predicted LAI $\left(\mathrm{R}^{2} \mathrm{CV}\right)$. Finally, the Wilcoxon signed-rank test was used to compare the distributions of predicted LAI values, according to the crop-specific (CS) and mixed-crop (MC) parameterization, and to identify statistical differences between the two parameterization approaches.

\subsection{Temporal Consistency}

For assessment of the temporal consistency of the estimated LAI against the measured LAI, the 2019 ground-LAI data set was used. First, the LAI time-series from the Sentinel-2 L2A data from October 2018 to October 2019 were retrieved, in order to cover the entire reference period. Then, the temporal consistency was evaluated.

To assess the temporal consistency of the predicted LAI for the temporal profiles, one representative ESU per crop was randomly selected. Subsequently, in order to obtain a full time-series, the ESU profile was interpolated and smoothed using the GPR method. Then, profiles of the retrieved LAI were compared with the measured ground-LAI and the related standard errors. The temporal profile was filtered using the Decomposition and Analysis of Time Series software (DATimeS) [56].

\section{Results}

\subsection{Seasonal Variation of Ground-LAI}

During the two growing seasons (i.e., 2018 and 2019), different ranges of ground-LAI values were measured within the three farms for each crop type (Figure 3 ).

During 2018, for winter wheat (C1) (Figure 3a), the minimum $(0.75 \pm 0.11)$ and maximum (4.67 \pm 0.95$)$ values of ground-LAI were observed at the San Piero farm (F1), at DOY 84 and 109, respectively. Meanwhile, in 2019 (Figure 3b), the minimum (1.52 \pm 0.33 ) and maximum $(5.54 \pm 0.68)$ ground-LAI values of $\mathrm{C} 1$ were observed at DOY 56 and DOY 106 at the Coltano farm (F3), respectively.

Regarding maize (C2) (Figure 3c,d), the minimum ground-LAI value for 2018 $(1.10 \pm 0.48)$ was observed at DOY 208, while that for 2019 was observed at DOY 190 $(1.32 \pm 0.50)$, while the maxima for $2018(5.21 \pm 2.52)$ and $2019(4.37 \pm 0.83)$ were at DOY 241 and 248 , respectively.

For alfalfa (C3), in 2018 (Figure 3e) the minimum ground-LAI was $0.88( \pm 0.26)$ at F1 (DOY 163) and the maximum was $9.41( \pm 0.80)$ at F3 (DOY 263). During 2019 (Figure 3f), at F3 the ground-LAI ranged between $1.64( \pm 0.40)$ and $5.10( \pm 0.59)$ at DOY 191 and 106 , respectively. 
ground-LAl dynamic of winter wheat (C1), maize (C2) and alfalfa (C3)
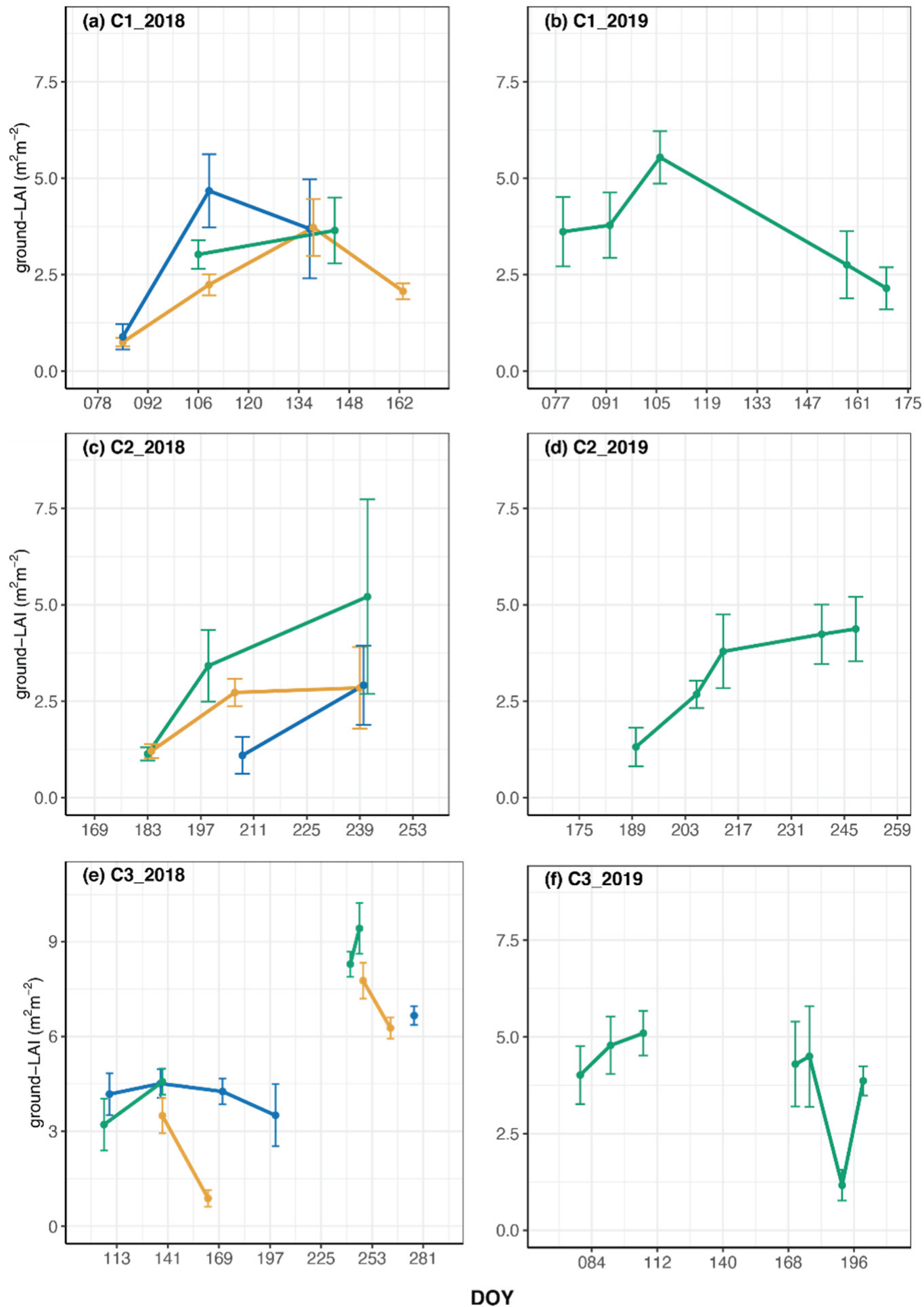

$$
\text { farm } \multimap F 1 \multimap F 2 \multimap F 3
$$

Figure 3. Mean values of the measured ground-LAI values of winter wheat (C1), maize (C2), and alfalfa (C3), according to the main crop development stages. The growing stages for winter wheat and maize are: SE, stem elongation; Fl, flowering; and FD, fruit development. For alfalfa, the growing stages are: $\mathrm{Vg}$, vegetative; $\mathrm{Fl}$, flowering. 


\subsection{Model Implementation and Accuracy}

\subsubsection{Parametric Model}

To evaluate the predictability of LAI by VIs (NDVI, SeLI, and NBR), the accuracy of the three-parameter logistic $\left(\operatorname{LogIF} \mathrm{d}_{\mathrm{d}}\right)$ and linear $(\mathrm{LM})$ functions were assessed over the crop-specific (CS) and mixed-crop (MC) parameterizations. Moreover, the LM and $\log \mathrm{IF}_{\mathrm{d}}$ MC parameterizations were assessed and compared at pixel and field level, in order to assess the suitability of VIs for the prediction of LAI in a mixed-crop scenario.

Table 4 shows the results of the accuracy of the parametric functions at pixel level. In general, it was observed that the LM showed statistical differences between the predicted LAI values for both mixed-crop and crop-specific parameterizations ( $p$-value $<0.05)$. In contrast, $\log \mathrm{IF}_{\mathrm{d}}$ showed that there were no statistical differences between the two parameterizations based on NBR for winter wheat (C1), NDVI for maize (C2), and SeLI for alfalfa (C3) ( $p$-value > 0.05). Overall, the two parametric methods showed $\mathrm{R}^{2} \mathrm{CV}$ values lower than 0.73 for the three VIs. For the LM, the coefficient of determinations were similar under both the CS and MC parameterizations, with a lower $\mathrm{RMSE}_{\mathrm{CV}}$ under CS parameterization in all the three crops for each VI. Conversely, the $\mathrm{R}^{2} \mathrm{CV}$ and $\mathrm{RMSE}_{\mathrm{CV}}$ of the $\operatorname{LogIF}_{\mathrm{d}}$ model showed differences between mixed-crop and crop-specific parameterizations for all three crops. Both of the parametric methods showed low accuracy in C3, regardless of the VIs and the parameterization data set. With the LM, the strongest accuracy of predicted LAI values of $\mathrm{C} 1$ was obtained using NBR with the CS parameterization $\left(\mathrm{R}^{2} \mathrm{CV}=0.72 ; \mathrm{RMSE}_{\mathrm{CV}}=0.68\right)$ and using SeLI with the MC parameterization $\left(\mathrm{R}^{2} \mathrm{CV}=0.72 ; \mathrm{RMSE}_{\mathrm{CV}}=0.73\right)$. Instead, when using the $\operatorname{LogIF}$ in $\mathrm{C} 1, \mathrm{NBR}$ showed the highest accuracy in both the cases of CS $\left(\mathrm{R}^{2} \mathrm{CV}=0.72 ; \mathrm{RMSE}_{\mathrm{CV}}=0.98\right)$ and $\mathrm{MC}\left(\mathrm{R}^{2} \mathrm{CV}=0.73 ; \mathrm{RMSE}_{\mathrm{CV}}=0.75\right)$ parameterizations.

Table 4. Cross-validation results of LAI estimation at pixel level from SeLI, NDVI, and NBR using the linear function (LM) and the inverse function improved with the conditional statement $\mathrm{d}\left(\log \mathrm{IF}_{\mathrm{d}}\right)$. The table reports, for each crop $(\mathrm{C} 1=$ winter wheat, $\mathrm{C} 2$ = maize, and C3 = alfalfa), the metrics obtained, according to the parameterization made on the crop-specific (CS) and the mixed-crop (MC) data sets. The table reports the mean of coefficient of determination $\left(\mathrm{R}^{2} \mathrm{CV}\right)$ and root mean square error $\left(\mathrm{RMSE}_{\mathrm{CV}}\right)$ estimated from the $\mathrm{k}$-fold cross validation procedure $(k=3)$; as well as the slope and the intercept of regression lines. The $p$-values $<0.05\left(^{*}\right),<0.01\left(^{* *}\right)$, and $<0.001\left(^{* * *}\right)$ indicate significant differences between the predicted LAI with MC and CS data sets.

\begin{tabular}{|c|c|c|c|c|c|c|c|c|c|c|c|}
\hline \multirow{2}{*}{ Function } & \multirow{2}{*}{ Metrics } & \multirow{2}{*}{ Data Set } & \multicolumn{3}{|c|}{ C1 } & \multicolumn{3}{|c|}{$\mathrm{C} 2$} & \multicolumn{3}{|c|}{$\mathrm{C} 3$} \\
\hline & & & NBR & NDVI & SeLI & NBR & NDVI & SeLI & NBR & NDVI & SeLI \\
\hline \multirow{9}{*}{$\mathrm{LM}$} & \multirow{2}{*}{$\mathrm{R}_{\mathrm{CV}}{ }^{2}$} & CS & 0.73 & 0.72 & 0.73 & 0.66 & 0.64 & 0.65 & 0.08 & 0.14 & 0.17 \\
\hline & & $\mathrm{MC}$ & 0.73 & 0.72 & 0.73 & 0.65 & 0.64 & 0.65 & 0.08 & 0.14 & 0.17 \\
\hline & \multirow{2}{*}{$\mathrm{RMSE}_{\mathrm{CV}}$} & CS & 0.68 & 0.73 & 0.72 & 0.81 & 0.89 & 0.88 & 0.67 & 0.80 & 0.84 \\
\hline & & $\mathrm{MC}$ & 0.76 & 0.83 & 0.72 & 0.94 & 1.07 & 1.12 & 0.99 & 0.96 & 0.87 \\
\hline & \multirow{2}{*}{ Intercept } & CS & 0.65 & 0.54 & 0.52 & 0.98 & 0.77 & 0.77 & 4.15 & 3.92 & 3.83 \\
\hline & & $\mathrm{MC}$ & 1.17 & 0.80 & 0.81 & 1.21 & 0.92 & 1.12 & 2.85 & 2.87 & 2.72 \\
\hline & \multirow{2}{*}{ Slope } & CS & 0.69 & 0.72 & 0.73 & 0.60 & 0.64 & 0.65 & 0.10 & 0.15 & 0.17 \\
\hline & & $\mathrm{MC}$ & 0.76 & 0.82 & 0.73 & 0.69 & 0.78 & 0.82 & 0.15 & 0.18 & 0.18 \\
\hline & $p$-value & CS vs. MC & 0.00 & 0.00 & 0.00 & 0.00 & 0.00 & 0.00 & 0.00 & 0.00 & 0.00 \\
\hline \multirow{9}{*}{$\operatorname{LogIF}_{\mathrm{d}}$} & \multirow{2}{*}{$\mathrm{R}_{\mathrm{CV}}{ }^{2}$} & CS & 0.72 & 0.70 & 0.62 & 0.60 & 0.59 & 0.55 & 0.05 & 0.04 & 0.09 \\
\hline & & MC & 0.73 & 0.72 & 0.65 & 0.64 & 0.62 & 0.65 & 0.02 & 0.03 & 0.05 \\
\hline & \multirow{2}{*}{$\mathrm{RMSE}_{\mathrm{CV}}$} & CS & 0.98 & 1.09 & 1.33 & 1.00 & 1.14 & 1.31 & 0.84 & 1.27 & 1.46 \\
\hline & & $\mathrm{MC}$ & 0.75 & 0.86 & 0.85 & 0.93 & 1.16 & 1.23 & 1.02 & 1.32 & 1.41 \\
\hline & \multirow{2}{*}{ Intercept } & CS & 0.23 & 0.20 & 0.16 & 0.55 & 0.60 & 0.60 & 2.13 & 2.53 & 2.43 \\
\hline & & $\mathrm{MC}$ & 0.43 & 0.29 & 0.25 & 0.50 & 0.54 & 0.58 & 2.39 & 2.71 & 2.61 \\
\hline & \multirow{2}{*}{ Slope } & $\mathrm{CS}$ & 0.97 & 1.03 & 1.05 & 0.65 & 0.71 & 0.76 & 0.11 & 0.16 & 0.22 \\
\hline & & $\mathrm{MC}$ & 0.77 & 0.85 & 0.73 & 0.67 & 0.78 & 0.89 & 0.09 & 0.15 & 0.15 \\
\hline & $p$-value & CS vs. MC & 0.51 & 0.00 & 0.00 & 0.01 & 0.60 & 0.24 & 0.00 & 0.00 & 0.14 \\
\hline
\end{tabular}


With the LM function in C2, the highest precision was obtained by NBR for both CS $\left(\mathrm{R}^{2} \mathrm{CV}=0.66 ; \mathrm{RMSE}_{\mathrm{CV}}=0.81\right)$ and $\mathrm{MC}\left(\mathrm{R}^{2} \mathrm{CV}=0.65 ; \mathrm{RMSE}_{\mathrm{CV}}=0.94\right)$ parameterizations. Regarding the case of the $\operatorname{LogIF}_{\mathrm{d}}$ function, instead, the highest accuracy was obtained by SeLI for the CS parameterization $\left(R^{2} C V=0.65 ; R_{M S E}=1.23\right)$ and by $N B R\left(R_{C V}^{2}=0.60\right.$; $\left.R M S E_{C V}=0.93\right)$ for the MC parameterization. Conducting a comparison among all three of the crops, LM exhibited the weakest accuracy in C3, considering all the VIs, with a coefficient of regression lower than 0.17. Analyzing the slope and the intercept of the regression equation, it can be argued that the LM led to overestimation, particularly in the case of low LAI values, independent of the VIs and the parameterization data set used. On the other hand, $\log _{\mathrm{IF}}$ strongly overpredicted when the LAI value was in the high-medium range.

In $\mathrm{C} 1$, when using SeLI in both parameterizations, the intercepts showed low values $\left(\mathrm{CS}=0.52\right.$ and $\mathrm{MC}=0.81$ for $\mathrm{LM} ; \mathrm{CS}=0.16$ and $\mathrm{MC}=0.25$ for $\left.\log _{\mathrm{IF}}\right)$; $\log _{\mathrm{d}}$ even exhibited values strictly close to 0 . At the same time, in the presence of medium-high LAI values, the slope of SeLI also tended to overpredict under the CS parameterization with a value of 1.05 and underpredicted for MC parameterization with a value of 0.73 .

In the case of $\mathrm{C} 2$, a completely different performance was obtained, according to the two functions and the three VIs; in fact, in the case of LM, the lowest intercept was obtained with NDVI for both parameterizations $(\mathrm{MC}=0.77$; $\mathrm{CS}=0.92)$. In the $\mathrm{Log}_{\mathrm{d}} \mathrm{I}_{\mathrm{C}}$, the lowest intercept was obtained with NBR for both parameterizations $(\mathrm{MC}=0.55 ; \mathrm{CS}=0.50)$.

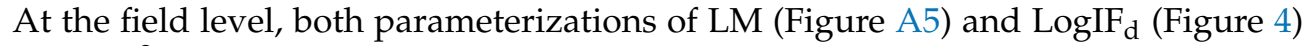
showed an $\mathrm{R}^{2}$ value higher than 0.8 for both $\mathrm{C} 1$ and $\mathrm{C} 2$. When $\mathrm{LM}$ was used, in both $\mathrm{C} 1$ and C2, the highest accuracy for the MC parameterization was obtained with SeLI, whose $\mathrm{R}^{2} \mathrm{CV}$ was equal to 0.88 and 0.82 for $\mathrm{C} 1$ and $\mathrm{C} 2$, respectively. Otherwise, for $\mathrm{C} 1$ and $\mathrm{C} 2$ in the $\mathrm{MC}$ parameterization, $\log \mathrm{IF}_{\mathrm{d}}$ showed a higher performance using NBR, presenting $\mathrm{R}^{2} \mathrm{CV}$ values equal to 0.87 and 0.85 , respectively.

\subsubsection{Non-Parametric Model}

Even for non-parametric models, MLRAs were trained over the crop-specific (CS) and mixed-crop (MC) data sets, in order to evaluate and compare the accuracy of LAI prediction at pixel level. Table 5 shows the accuracy metrics of MLRAs at the pixel level. In general, the GPR showed the highest $\mathrm{R}^{2} \mathrm{CV}$ and the lowest $\mathrm{RMSE}_{\mathrm{CV}}$ for each training data set of all the three crops, except for C2. In fact, when BAGTREE was used in the mixed-crop data set of $\mathrm{C} 2$, the $\mathrm{R}^{2} \mathrm{CV}$ was 0.62 , compared to 0.59 under GPR, and the RMSE $\mathrm{CV}_{\text {vas }} 1.02 \mathrm{vs}$. 1.06 of GPR. When GPR was used in C3, the estimated values were slightly overestimated; indeed, the values of the intercept higher than 1 confirmed this overprediction. However, despite the overestimation of low-LAI values with GPR, the slope values close to 1 highlighted that there was a positive linear relationship between the measured and predicted values.

Overall, the MLRAs showed a higher accuracy of prediction at pixel level than parametric methods, and it was also observed that GPR did not provide any significant difference between the predicted LAI values according to the MC and CS data sets, regardless of the considered crop. The higher efficacy of MRLAs, in terms of the estimation of LAI under both the MC and CS data sets, was also observed at the field level (Figure 5). Indeed, GPR obtained an $\mathrm{R}^{2} \mathrm{CV}$ value higher than 0.80 for all the crops.

\section{GPR Spectral Band Relevance}

The graphs shown in Figure 6 synthesize the analysis performed to evaluate the relevance of S2 spectral bands to the different GPR models for LAI estimation, according to crop development stages for the "crop-specific model" and crop type for the "mixedcrop model". 

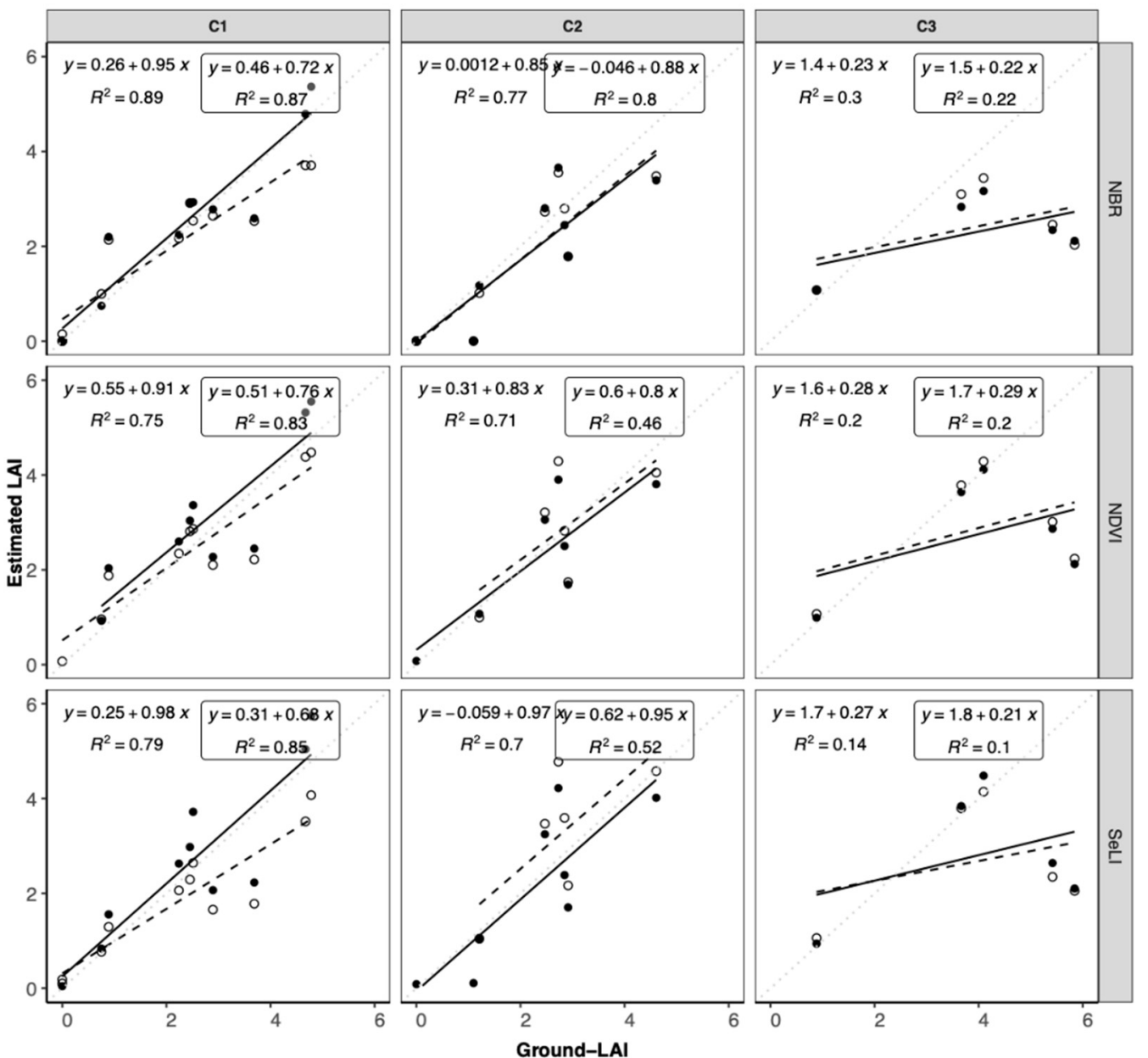

Figure 4. Validation results of LAI estimation at field level from SeLI, NDVI, and NBR by the inverse function improved with the conditional statement $d(\operatorname{LogIF} d)$. Results per crop $(\mathrm{C} 1, \mathrm{C} 2$, and $\mathrm{C} 3)$ of linear regression analysis between measured

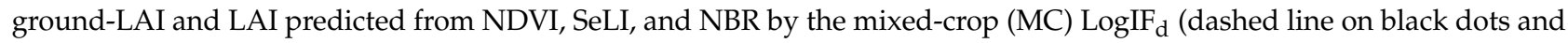
equation in the box) and the crop-specific (CS) $\operatorname{LogIF}_{\mathrm{d}}$ (continuous line on white dots).

Table 5. Cross-validation results of LAI estimation at pixel level from GPR, BOOST, and BAGTREE. The table reports, for each crop $(\mathrm{C} 1$ = winter wheat, $\mathrm{C} 2$ = maize, and $\mathrm{C} 3=$ alfalfa $)$, the metrics obtained according to the parameterization made on the crop-specific (CS) and the mixed-crop (MC) data sets. The table reports the mean of coefficient of determination $\left(\mathrm{R}^{2} \mathrm{CV}\right)$ and root mean square error $\left(\mathrm{RMSE}_{\mathrm{CV}}\right)$ estimated from the $\mathrm{k}$-fold cross validation procedure $(\mathrm{k}=3)$; as well as the slope and the intercept of regression lines. $p$-values $<0.05\left(^{*}\right),<0.01\left({ }^{* *}\right)$, and $<0.001\left({ }^{* *}\right)$ indicate significant differences between the predicted LAI with MC and CS data sets.

\begin{tabular}{|c|c|c|c|c|c|c|c|c|c|c|}
\hline \multirow{2}{*}{ Metrics } & \multirow{2}{*}{ Dataset } & \multicolumn{3}{|c|}{$\mathrm{C} 1$} & \multicolumn{3}{|c|}{$\mathrm{C} 2$} & \multicolumn{3}{|c|}{ C3 } \\
\hline & & GPR & BOOST & BAGTREE & GPR & BOOST & BAGTREE & GPR & BOOST & BAGTREE \\
\hline \multirow{2}{*}{$\mathrm{R}_{\mathrm{CV}}{ }^{2}$} & CS & 0.81 & 0.79 & 0.77 & 0.69 & 0.63 & 0.67 & 0.71 & 0.62 & 0.63 \\
\hline & MC & 0.77 & 0.63 & 0.74 & 0.59 & 0.58 & 0.62 & 0.65 & 0.62 & 0.62 \\
\hline \multirow{2}{*}{$\mathrm{RMSE}_{\mathrm{CV}}$} & CS & 0.65 & 0.68 & 0.66 & 0.84 & 1.04 & 0.87 & 1.00 & 1.22 & 1.04 \\
\hline & $\mathrm{MC}$ & 0.66 & 0.99 & 0.77 & 1.06 & 1.15 & 1.02 & 1.05 & 1.07 & 1.03 \\
\hline \multirow{2}{*}{ Intercept } & CS & 0.36 & 0.29 & 0.45 & 0.67 & 0.56 & 0.67 & 1.36 & 1.26 & 1.65 \\
\hline & MC & 0.51 & 0.43 & 0.55 & 0.72 & 0.77 & 0.75 & 1.42 & 1.61 & 1.52 \\
\hline \multirow{2}{*}{ Slope } & CS & 0.82 & 0.81 & 0.75 & 0.68 & 0.73 & 0.68 & 0.71 & 0.71 & 0.63 \\
\hline & MC & 0.75 & 0.81 & 0.80 & 0.69 & 0.72 & 0.70 & 0.65 & 0.61 & 0.59 \\
\hline$p$-value & CS vs. MC & 0.13 & 0.08 & 0.00 & 0.30 & 0.06 & 0.06 & 0.00 & 0.27 & 0.00 \\
\hline
\end{tabular}



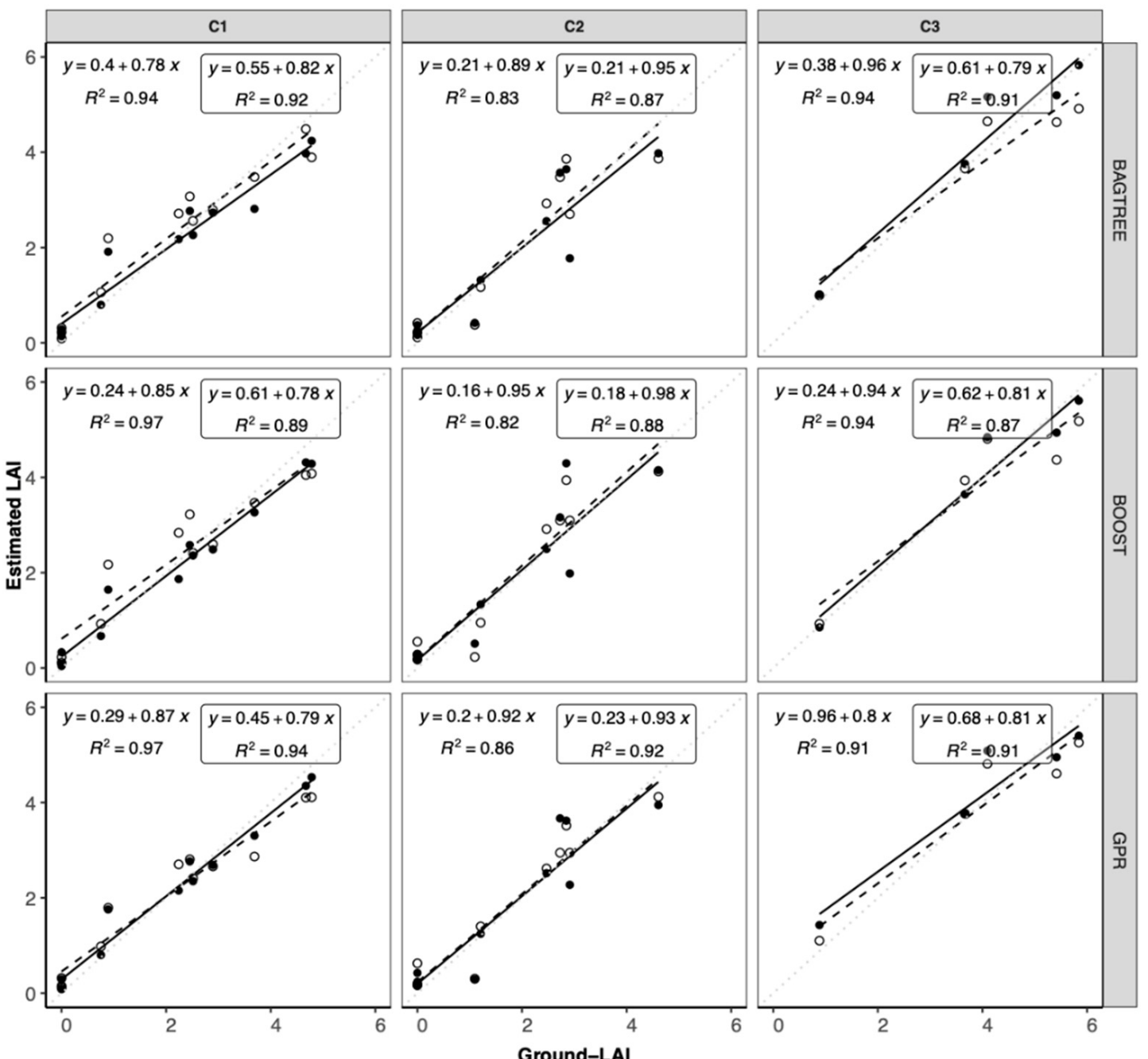

Figure 5. Validation results of LAI estimation at field level by GPR, BOOST, and BAGTREE. Results per crop (C1, C2, and C3) of the linear regression analysis between measured ground-LAI and LAI predicted from GPR, BOOST, and BAGTREE, according to the mixed-crop (MC) (dashed line on black dot and equation in the box) and crop-specific (CS) (continuous line on white dots) training data sets.

Regarding the crop-specific model, when C1 (winter wheat) (Figure 6a) was in the stem elongation (SE) stage, the highest relevant bands were in the red edge (RE) region, as B5 and B6 showed a spectral contribution of $22 \%$ and $23 \%$, respectively, for a total of more than $45 \%$. Conversely, during the flowering $(\mathrm{Fl})$ stage, a slight decrease of RE contribution (15\% B5 and 15\% B6), and a significant increase in the near-infrared (NIR) region (B7, B8, and $\mathrm{B} 8 \mathrm{~A}$ ), higher than $15 \%$, was observed. When $\mathrm{C} 1$ reached the fruit development (FD) stage, all bands in the VIS-NIR region had a similar relevance, ranging from $10 \%$ to $13 \%$ contribution, while those in the SWIR region (B11 and B12) showed values lower than $2 \%$.

When $\mathrm{C} 2$ (maize) (Figure 6b) was in the SE stage, the highest contribution was observed in the NIR (B7, B8, and B8A) and RE regions (B5 and B6), which reached a relevance higher than $10 \%$ (up to $14 \%$ ), while the lowest contribution was exhibited by the blue band (B2), with $0 \%$ relevance. During the Fl stage of C2, B8A (with about $14 \%$ ) showed the highest percentage of relevance, followed by B7 and B8 (with more than 12\%). During the FD stage of $C 2$, B8 showed the highest percentage of relevance (18\%), B2 also had a great contribution (17\%), as well as B7 and B6 (both about $14 \%$ ), while the contributions of other bands were all around or less than $5 \%$. 
(a) winter wheat (C.1) OSE OFI OFD

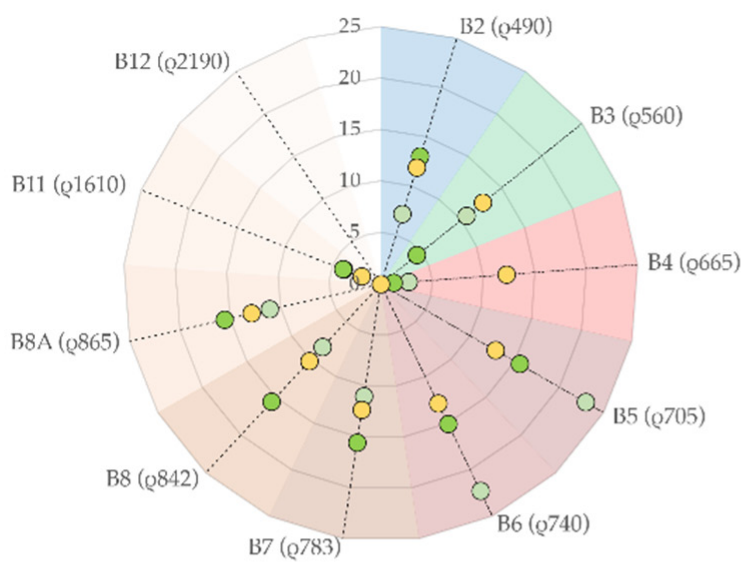

(c) alfalfa (C3)

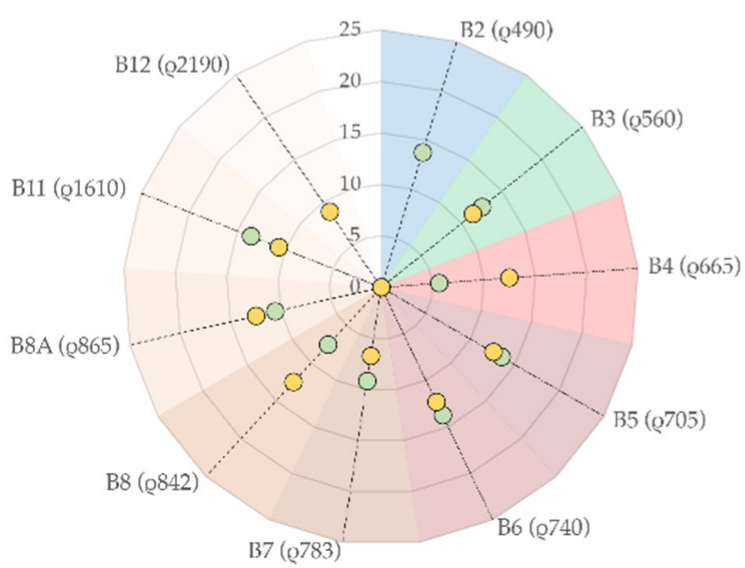

(b) maizc (C2) OSE OFl OFD

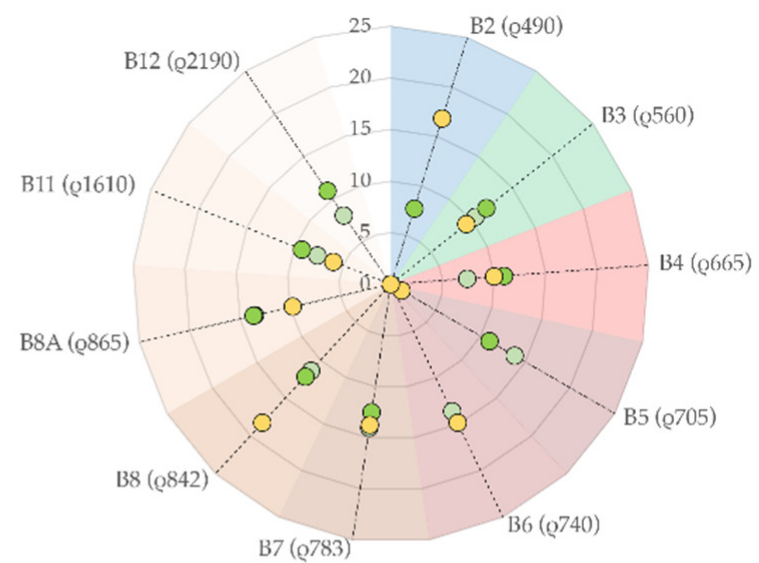

(d) mixed-crop $\quad \circ \mathrm{Cl} \bullet \mathrm{C}^{\circ} \bullet \mathrm{C} 3$

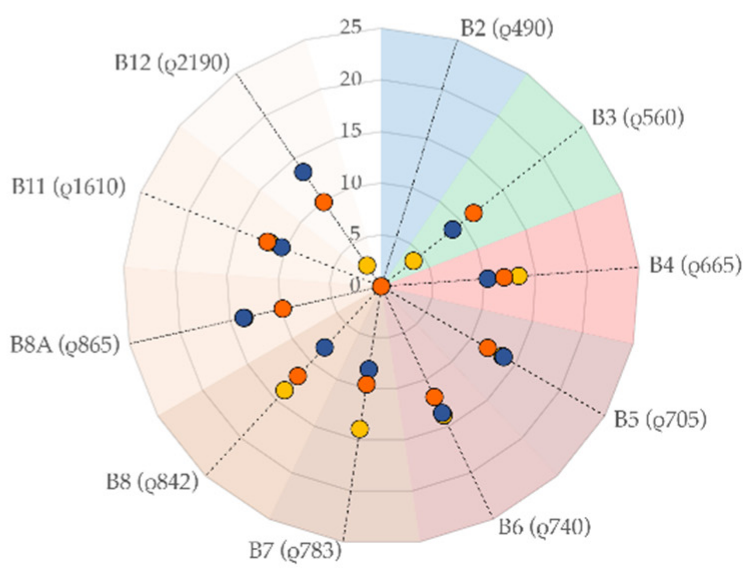

Figure 6. Radar plots of the relative weight (\%), estimated from $\sigma$ values provided by GPR analysis, of Sentinel-2 spectral bands to LAI estimation, according to: (i) different growing stages within the crop-specific data set for C1 (winter wheat), C2 (maize), and alfalfa (C3); and (ii) crop type within the mixed-crop data set. The growing stages for winter wheat and maize are: GE, from germination to emergence; SE, stem elongation; Fl, flowering; and FD, fruit development. For alfalfa, the growing stages were: $\mathrm{Vg}$, vegetative; and $\mathrm{Fl}$, flowering.

Apart from B2 (0\%) and B7 (7\%), when C3 (alfalfa) (Figure 6c) was in the vegetative stage (Vg), a uniform spectral contribution was observed across all of the spectrum, with a relevance higher than $10 \%$. When C3 was in the Fl stage, the lowest percentage was observed with respect to B4 (6\%) and the highest was with B6 (14\%).

Analysis of the mixed-crop data set (Figure 6d) by GPR showed that the RE and NIR regions provided the largest contribution (about 13\% for the spectral bands B5, B6, B7, B8, and B8A) for C1 LAI estimation. Regarding C2 LAI estimation, the most relevant bands were B6, B7, and B8A, with percentage higher than 13\%. In C3, the LAI model exploited all of the spectrum, with a similar contribution (higher than 10\%); except for B2, which was not relevant $(0 \%)$.

\subsection{Temporal Consistency of LAI estimation}

Using the data of the 2019 sampling campaign, the parametric function and nonparametric algorithm with the highest accuracy for LAI retrieval were selected for the temporal assessment. Figure 7 show the dynamics of the predicted LAI values compared with the measured ground-LAI of one representative ESU for each crop by LM, LogIF ${ }_{d}$, and GPR. In general, the predicted LAI profiles obtained from the GPR exhibited the closest 
predicted LAI values to the measured ground-LAI, while the parametric approaches based on LM and $\operatorname{LogIF}_{\mathrm{d}}$ showed different consistency of temporal dynamics, according to the crop type.
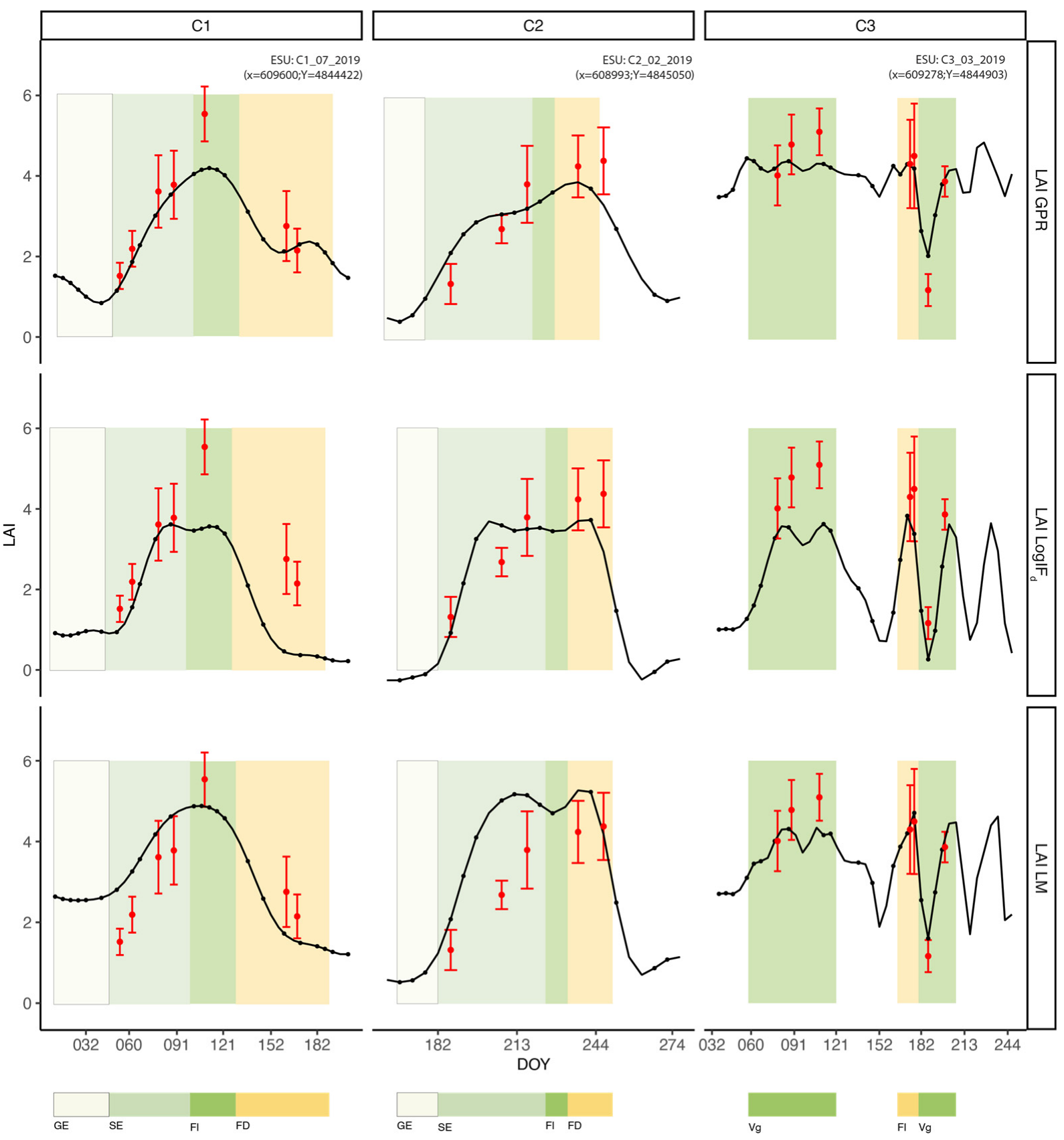

Figure 7. Temporal profile of LAI retrieved with GPR, LM, and $\log _{\mathrm{I}} \mathrm{F}_{\mathrm{d}}$ (black line), compared with the measured groundLAI (red dots). Black lines represent the smoothed temporal profile of each crop using the GPR interpolation method, while black dots are the available S2 images. Red bars represent the standard deviation of ground-LAI. Different colored areas indicate the duration of each growth stage. In winter wheat (C1) and maize (C2), the growth stages are: from germination to full emergence (GE); stem elongation (SE); flowering (Fl); and fruit development (FD). In alfalfa (C3), the growth stages are: vegetative (Vg), occurring after mowing and flowering; and ( $\mathrm{Fl}$ ) occurring at full canopy development before mowing. In the $x$-axis, the day of the year (DOY) is depicted.

Specifically, it was observed that $\operatorname{LogIF}_{\mathrm{d}}$ and GPR in the stem elongation (SE) stage of winter wheat (C1) showed a similar behavior, yielding predictions very close to the groundLAI values. Conversely, the LM exhibited the most distant predictions to the measured 
LAI. In $\mathrm{C} 1$ flowering (Fl) and fruit development (FD) stages, the closest predicted LAI values to ground-LAI were obtained using the GPR.

In maize (C2), GPR showed a LAI dynamic very similar to the one measured in situ, while LM and $\operatorname{LogIF}_{\mathrm{d}}$ overestimated the LAI, especially during SE. During the C2 FD stage, GPR and LogIF $\mathrm{d}_{\mathrm{d}}$ showed a similar behavior, both underestimating the predicted LAI values, while LM exhibited a slight overestimation tendency. In alfalfa (C3), during the earliest vegetative $(\mathrm{Vg})$ stage, LM showed the closest predicted LAI values to ground-LAI. During the Fl stage, GPR and LM showed similar performance.

\section{Discussion}

Considering spectral bands (e.g., near-infrared), indicators (e.g., NDVI), and final useful products (e.g., land-cover), there is a need to obtain valuable information for the development of LAI, as elaborated for the Copernicus indictors and products. Thus, assessment of the statistical relationship between ground-LAI and satellite remote sensing data for LAI prediction requires assessing the accuracy of LAI retrieval methods, according to ground-LAI estimation errors [42,57]. In this study, we measured ground-LAI for three crops, and showed a wide range of values, compared with those reported in the literature. Specifically, Revill et al. [58], using SunScan, exhibited a lower range of ground-LAI values ( $\min , 0.5 ; \max , 3.5$ ) for winter wheat. However, our field data covered the entire cycle, from emergence to maturity, and agreed with Upreti et al. [26] (min, 1; max, 6.5).

Regarding maize, Facchi et al. [59], using LAI-2000, a ceptometer, and a Hemispherical camera in an experiment to compare (with destructive sampling measurements) the range of maize ground-LAI, the results were comparable to those we sampled in the field ( $\mathrm{min}, 1$; $\max , 5$ ). Finally, for alfalfa, Verger et al. [60] measured a range of ground-LAI (min, 0.8 ; max, 6.5) that was lower with respect to our collected maxima (LAI > 8) using the LAI-2000 instrument. From this literature comparison, the only anomalous apparent difference of ground-LAI values was observed for alfalfa. However, the average value was coherent for different ESU in the same field for the 2018 sampling at flowering date (just before mowing) and, so, it was not in disagreement with the analysis. This difference, with respect to the literature, could arise from the uncertainty due to the optical instrument, the phenological stage, and the crop reflectance response [61,62].

Uncertainty of LAI estimations could arise from many factors, including crop type, farm management, and temporal variability of ground-LAI measurements [42,63].

In this work, we observed that, when using parametric approaches, SeLI proved to be the most suitable VI for LAI prediction under a mixed crop scenario. This result is in close agreement with previous findings highlighting that the combination of NIR and RE may provide more accurate LAI estimates for different crop types [18,34]. However, in the assessment of parametric methods, we also demonstrated that, at pixel level, the accuracy of LAI estimation was strongly affected not only by the VI selection but also (and not in a negligible manner) by the regression function as well as the parameterization data set $[20,63]$. The results of VIs also demonstrated the better LAI prediction ability of SeLI for wheat and maize, compared to alfalfa. The different LAI prediction ability of Vis, according to crop types, is in agreement with Herrmann et al. [64]. In this regard, Dong et al. [17], using RapidEye reflectance data and ground-LAI data of different crop types, demonstrated that VIs based on visible and RE regions are generally affected by chlorophyll, water content, and the structural properties of leaves and, therefore, the LAI predictability of a VI may vary markedly among crops and growing stages, according to canopy characteristics. Furthermore, when the crop-specific and mixed-crop parameterization were compared under both regression methods based on linear and logistic models $\left(\mathrm{LM}\right.$ and $\log \mathrm{IF}_{\mathrm{d}}$ ), we demonstrated that the parameterization data set strongly influenced the LAI prediction and its accuracy. This result built on the study of Nguy-Robertson et al. [20] who, using hyperspectral data, found that RE-based VIs are little affected by crop type and, thus, may facilitate the prediction of LAI for different crops characterized by different canopy structure. This finding is very important for the future availability of 
operational hyperspectral missions, such as the foreseen Copernicus CHIME and NASA SBG $[31,65]$. Thus, to obtain an accurate LAI prediction, the selection of suitable VIs is critical, as ideal VIs should be sensitive to the ground-LAI but insensitive to interference factors (e.g., the soil background, canopy structure, and chlorophyll content) [66]. Thus, despite the fact that SeLI yielded the most accurate results, it was also demonstrated that, due to the above-mentioned uncertainties, it might be not as accurate at pixel level.

Moreover, we showed how the three MLRAs (and, in particular, GPR) were able to exploit all information available from a multispectral data set, thus providing more accuracy in LAI prediction compared to VIs. Indeed, considering the relative weight of bands in the GPR algorithm, it was observed that, although the NIR and RE bands were the most relevant for LAI estimation, the other bands also contributed-varying according to the crop type and development stage-to LAI prediction. This finding is in agreement with previous outcomes. Delloy et al. [67] showed how the RE S2 bands (B5, B6, and B7) can improve winter wheat LAI estimation by using a hybrid approach (RTM + neural network). Verrelst et al. [13] compared different MLRAs, using simulated Sentinel-2 reflectance data over different crops types, and concluded that GPR was the most effective algorithm for LAI retrieval. However, despite the promising results of MLRAs, it was also observed that the performance was influenced by the training data set (i.e., MC vs. CS). This is in agreement with Mao et al. [25], who tested the influence of sample size on MLRA performances and highlighted how its influences the accuracy of the algorithms.

Regarding the temporal consistency of LAI estimation, our results showed that LAI retrieved by the parametric approach, at pixel level, was less suitable, with respect to the non-parametric approach. Indeed, the parametric method based on VIs showed a low accuracy, in terms of representing variability within the field, due to a saturation effect occurring especially at high vegetation density. In contrast, GPR allowed us to point out such variation, regardless of the crop development stage [58]. The low ability of parametric methods to account for the within variability of LAI was evidenced by the weak metrics of cross-validation carried out at pixel level. In particular, LM made it evident that parametric approaches may lead to the overestimation of LAI at early stages of crop development and underestimation at full canopy development. In this latter condition, VIs showed their limit in detecting LAI variation, due to the well-known issue of saturation [45] —a limit of VIs that was particularly exacerbated in the case of alfalfa, which reaches canopy closure, after resprouting, in less time compared to a winter cereal (wheat) and a row crop (maize). Conversely, GPR showed a high ability to detect LAI variation at the pixel level, regardless of the development stage, vegetation density, and crop type.

It is well-known that the canopy reflectance is affected by several biophysical and biochemical variables and, thus, the regions of the reflectance spectrum can be associated with different vegetation properties $[68,69]$. Therefore, exploitation of the full spectrum with non-parametric methods can improve the quality of LAI retrieval [13]. Indeed, our results demonstrated that the GPR outperformed the parametric methods; in addition, it was the most accurate MLRA for LAI prediction at both field and pixel level. The results of this study showed that the VI-based parametric method had a lower accuracy for LAI retrieval than MLRAs. These results suggest that GPR based on Sentinel-2 multispectral images is promising for crop monitoring, from a multi-crop mosaic scenario perspective. Further work will involve applying the MLRAs trained in this work to verify the model stability when applied to an independent data set; this analysis will allow for a full assessment of the robustness and exportability of the model developed.

The capacity of MLRAs to deal with full spectral information is a promising aspect that makes these approaches candidates for the investigation of new-generation hyperspectral data available from ASI-PRISMA, as well as those expected from the foreseen Copernicus CHIME and NASA SBG missions. 


\section{Conclusions}

In the present study, the capability of different parametric and non-parametric methods for the retrieval of LAI for different arable crops using Sentinel-2 data was assessed. The accuracy and robustness of LAI estimates were compared, based on repeated in situ ground-LAI measurements throughout the crop growing season. Regarding the VI-based parametric regressions, the normalized index SeLI was evaluated as more suitable (i.e., than NDVI and NBR) for LAI retrieval at field level, providing good evaluation metrics by the cross-validation analysis for winter wheat and maize. However, VI-based parametric methods were shown: (i) to be unsuitable for LAI retrieval of alfalfa and mixed crop scenario; (ii) to have a very low accuracy for LAI retrieval at pixel level; and (iii) to have an accuracy of prediction the largely depends on VI selection, the fitting function, and the parameterization data set.

Among the non-parametric regression methods evaluated, the best-performing MLRA belonged to the kernel machine learning regression algorithms. Indeed, GPR was evaluated as the best-performing algorithm for LAI prediction, for the three arable crops evaluated. Using GPR, Sentinel-2 imagery can be used to map the spatial variability of the LAI of different arable crops, having prediction accuracy which is very high at the pixel level regardless of the crop type, growth stage, and the training data set. Moreover, GPR analysis of spectral bands in different phenological stages provided information on the relevance of relative bands in contributing to LAI prediction. However, further studies are required to fully assess the potential of GPR across different crops in different areas, as well as under contrasting agronomic conditions.

Author Contributions: Conceptualization, M.D.P., A.T. (Andrea Taramelli) and G.R.; methodology, M.D.P., A.T. (Andrea Taramelli), M.B., A.M., F.F. and G.R.; investigation, M.D.P., A.T. (Andrea Taramelli), M.B. and G.R.; data curation, M.D.P., A.M., F.F., I.V. and G.R.; writing—original draft preparation, M.D.P., A.M., F.F., I.V. and G.R.; writing-review and editing, M.D.P., A.T. (Andrea Taramelli), M.B., A.M., I.V., F.F., A.T. (Antonella Tornato), E.V. and G.R.; supervision, A.T. (Andrea Taramelli) and G.R. All authors have read and agreed to the published version of the manuscript.

Funding: The research was funded by the European Commission, ruled by Contract No. 4000125506/ 18/NL/IA "CHIME Mission Requirements Consolidation study", and the exploitation of results has been funded by the Italian Institute for Environmental Protection and Research (ISPRA) in the framework of agreement between ISPRA and Italian Space Agency (ASI) on "Air Quality" (Agreement number F82F17000000005) and by the Tuscany Region 2014-2020-Submeasure 16.5 PANACEA (CUP 787563).

Institutional Review Board Statement: Not applicable.

Informed Consent Statement: Not applicable.

Data Availability Statement: Data supporting the findings of this study are available on request from the corresponding author.

Acknowledgments: The authors wish to thank the staff from SSSA for trial management and ISPRA for their valuable support in the pre-processing stage of Sentinel-2 data.

Conflicts of Interest: The authors declare no conflict of interest. 


\section{Appendix A}
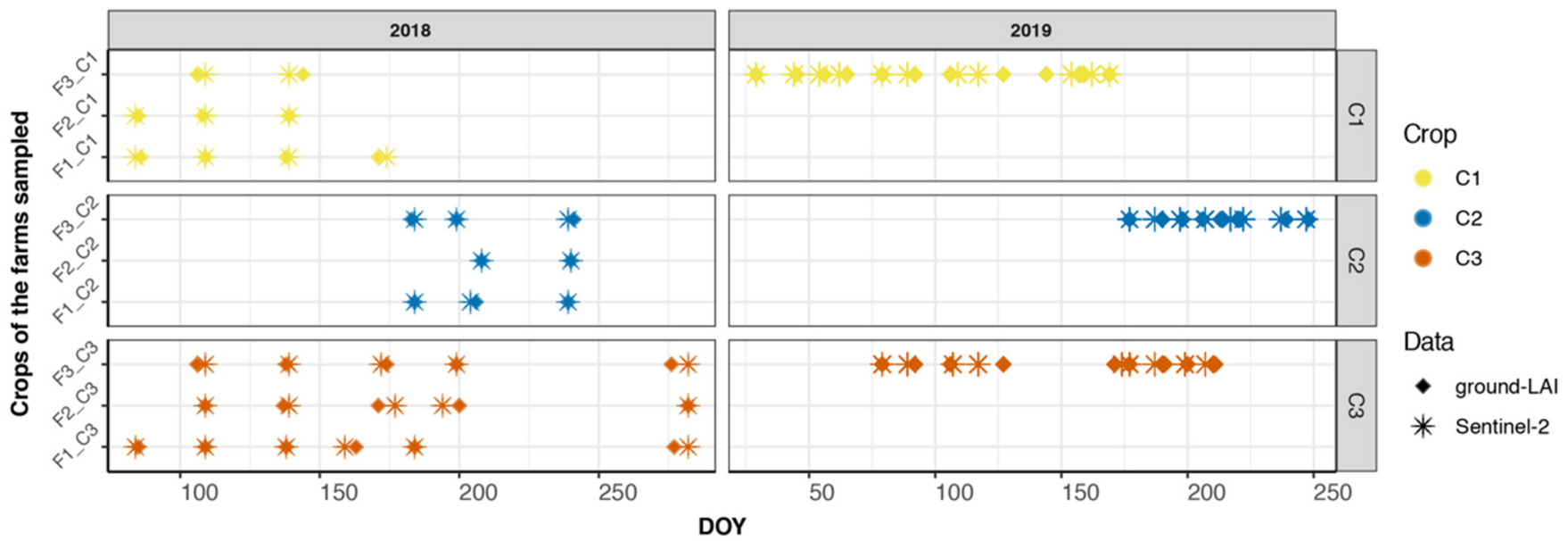

Figure A1. Sentinel-2 data (total, 37 images) acquired during the 2018 and 2019 crop seasons (C1, winter wheat; C2, maize; $\mathrm{C} 3$, alfalfa) and the ground-LAI acquisitions in the experimental sites F1, F2, and F3, around Pisa; DOY is day of the Year.

Table A1. Wavelength and spatial resolution of Sentinel-2 spectral bands.

\begin{tabular}{|c|c|c|c|c|}
\hline Spatial Resolution & Band & Name & $\begin{array}{c}\text { Central } \\
\text { WavelengthSentinel-A (nm) }\end{array}$ & $\begin{array}{c}\text { Central } \\
\text { WavelengthSentinel-B (nm) }\end{array}$ \\
\hline \multirow{4}{*}{ Resolution $10 \mathrm{~m}$ : } & B02 & Blue & 492.4 & 492.1 \\
\hline & B03 & Green & 559.8 & 559.0 \\
\hline & B04 & Red & 664.6 & 664.9 \\
\hline & B08 & NIR & 832.8 & 832.9 \\
\hline \multirow{6}{*}{ Resolution $20 \mathrm{~m}$ : } & B05 & Red Edge 1 & 704.1 & 703.8 \\
\hline & B06 & Red Edge 2 & 740.1 & 739.8 \\
\hline & B07 & Red Edge 3 & 782.8 & 779.7 \\
\hline & B8A & Vegetation Red Edge & 864.7 & 864.0 \\
\hline & B11 & SWIR 1 & 1613.7 & 1610.4 \\
\hline & B12 & SWIR 2 & 2202.4 & 2185.7 \\
\hline \multirow{3}{*}{ Resolution $60 \mathrm{~m}$ : } & B01 & Aerosols & 442.7 & 442.2 \\
\hline & B09 & Water vapor & 945.1 & 943.2 \\
\hline & B10 & Cirrus & 1373.5 & 1376.9 \\
\hline
\end{tabular}

Table A2. Standard configuration of MLRAs using the ARTMO toolbox.

\begin{tabular}{cccc}
\hline Parameter & GPR & BOOST & BAGTREE \\
\hline fit method & exact & \\
basis function & constant & \\
computational method & qr \\
kernel function & Squared Exponential Kernel & \\
maximum number of trees & & 200 & 200 \\
\hline
\end{tabular}



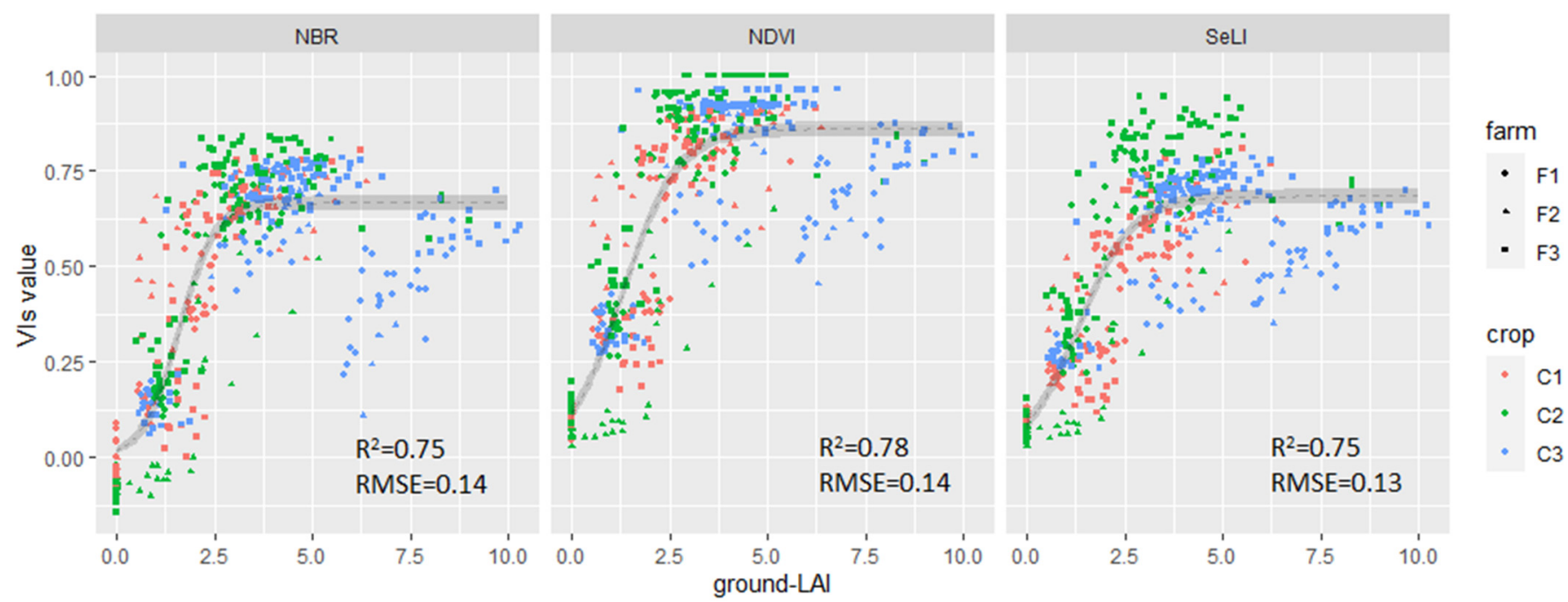

Figure A2. Non-linear regression between ground-LAI and VIs (NBR, NDVI, and SeLI), according to the three-parameter logistic function (L.3). Dashed line corresponds to the regression curve, while colored dots are the three crops: Yellow for winter wheat (C1), blue for maize (C2), and orange for alfalfa (C3). The shapes represent the farms (F1, F2 and F3).
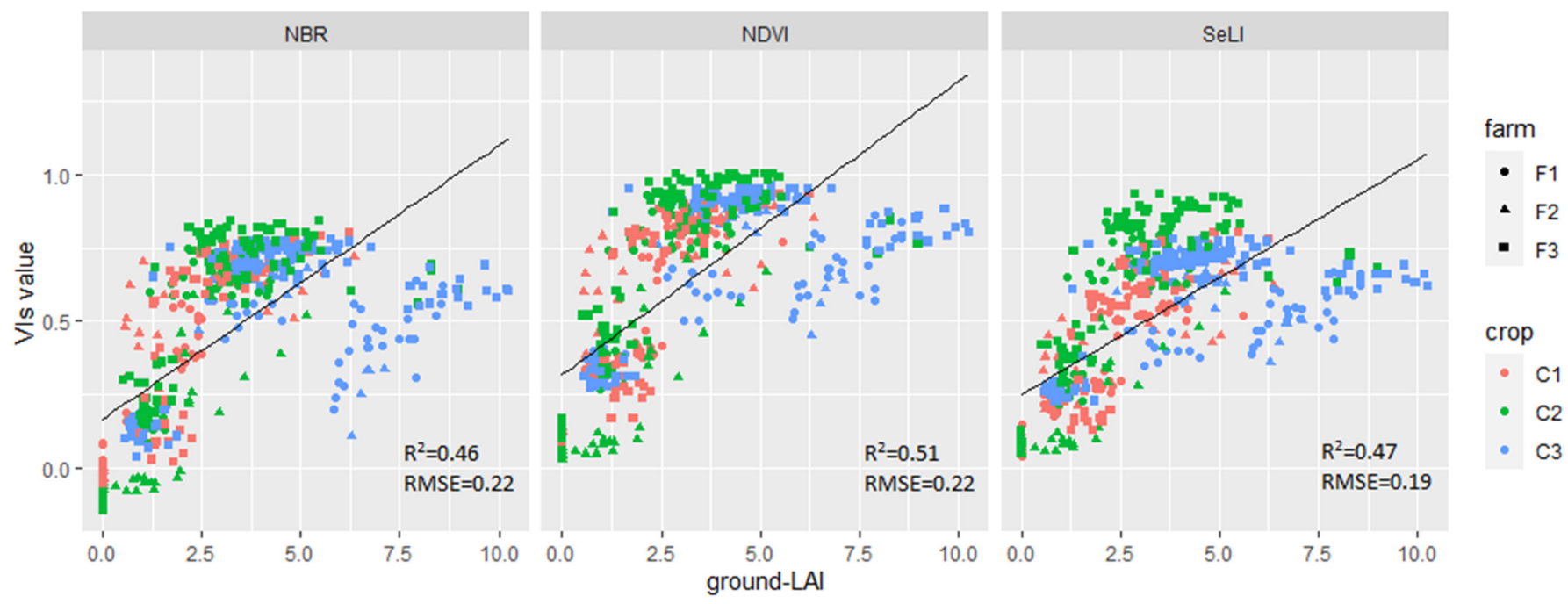

Figure A3. Linear regression between ground-LAI and VIs (NBR, NDVI, and SeLI), according to the Linear function (LM). Dashed line corresponds to the regression curve, while colored dots are the three crops: yellow for winter wheat (C1), blue for maize (C2), and orange for alfalfa (C3). The shapes represent the farms (F1, F2, and F3). 
Spectral profile of VIs (2018)
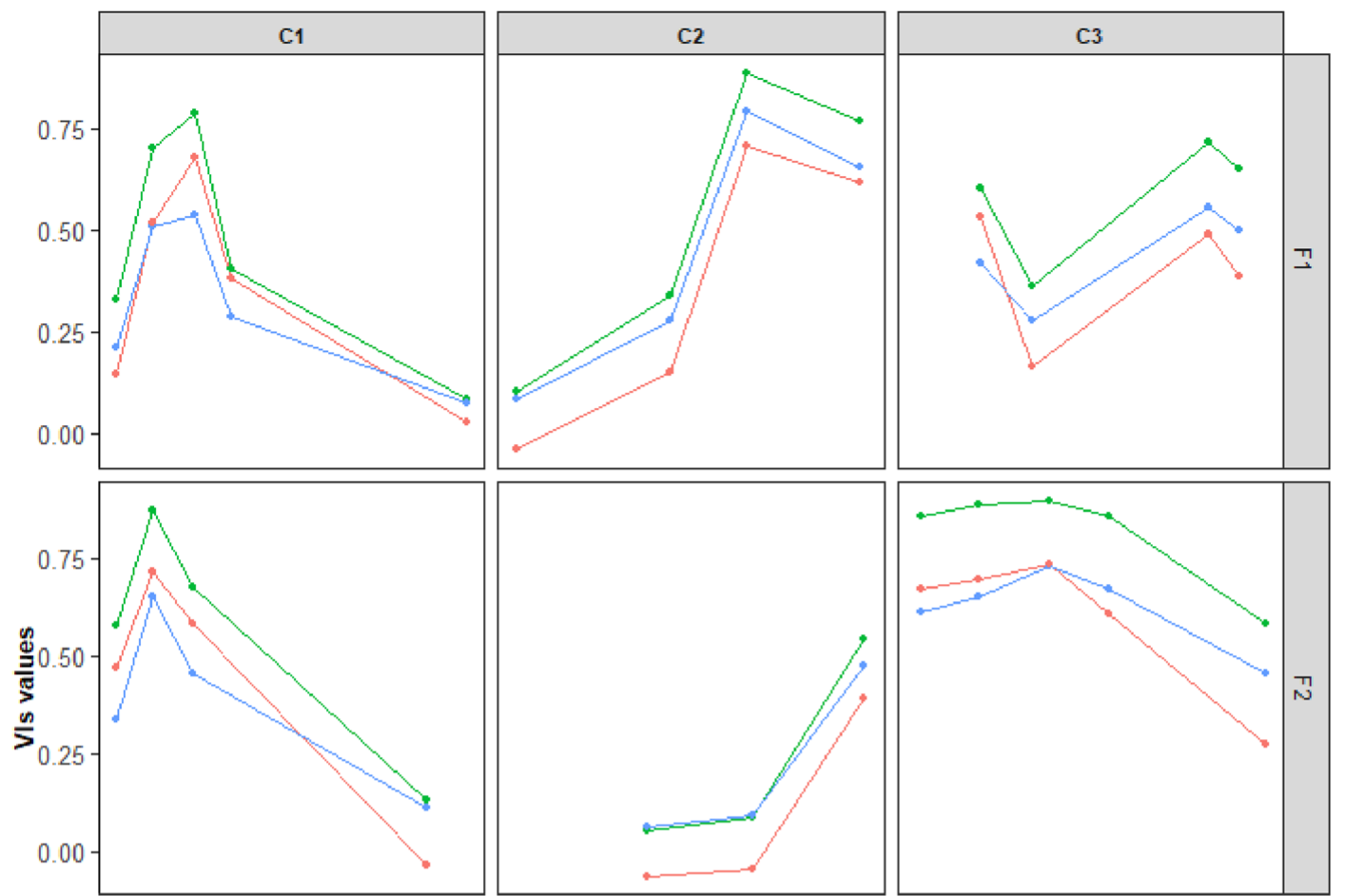

VIs

$\rightarrow$ NBR

$\rightarrow$ NDVI

$\rightarrow$ SeLI
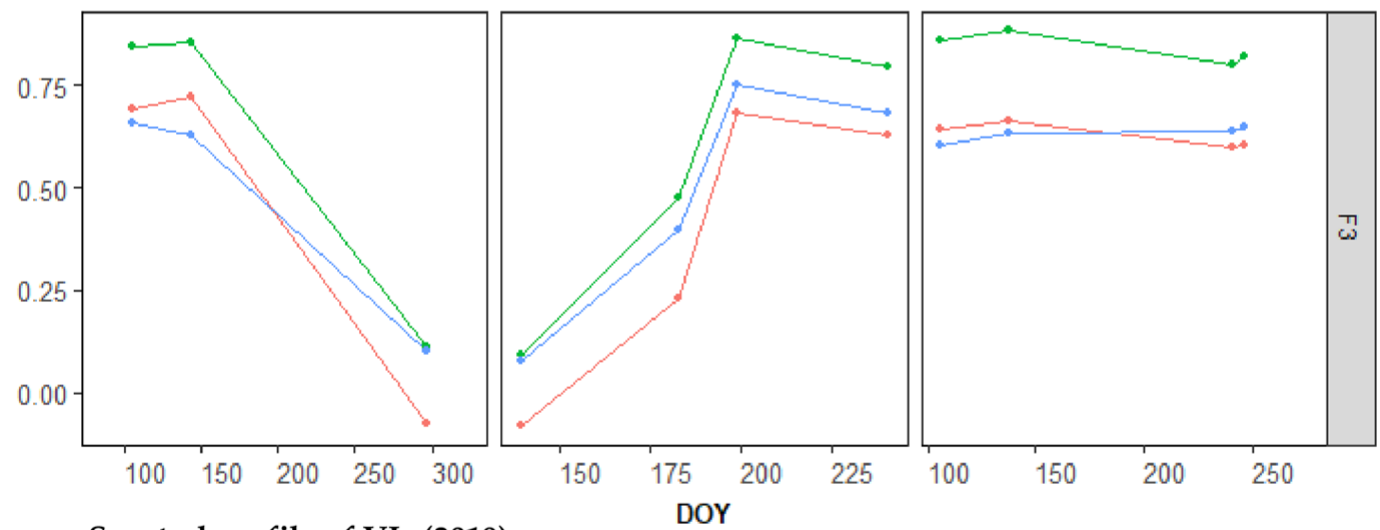

Spectral profile of VIs (2019)
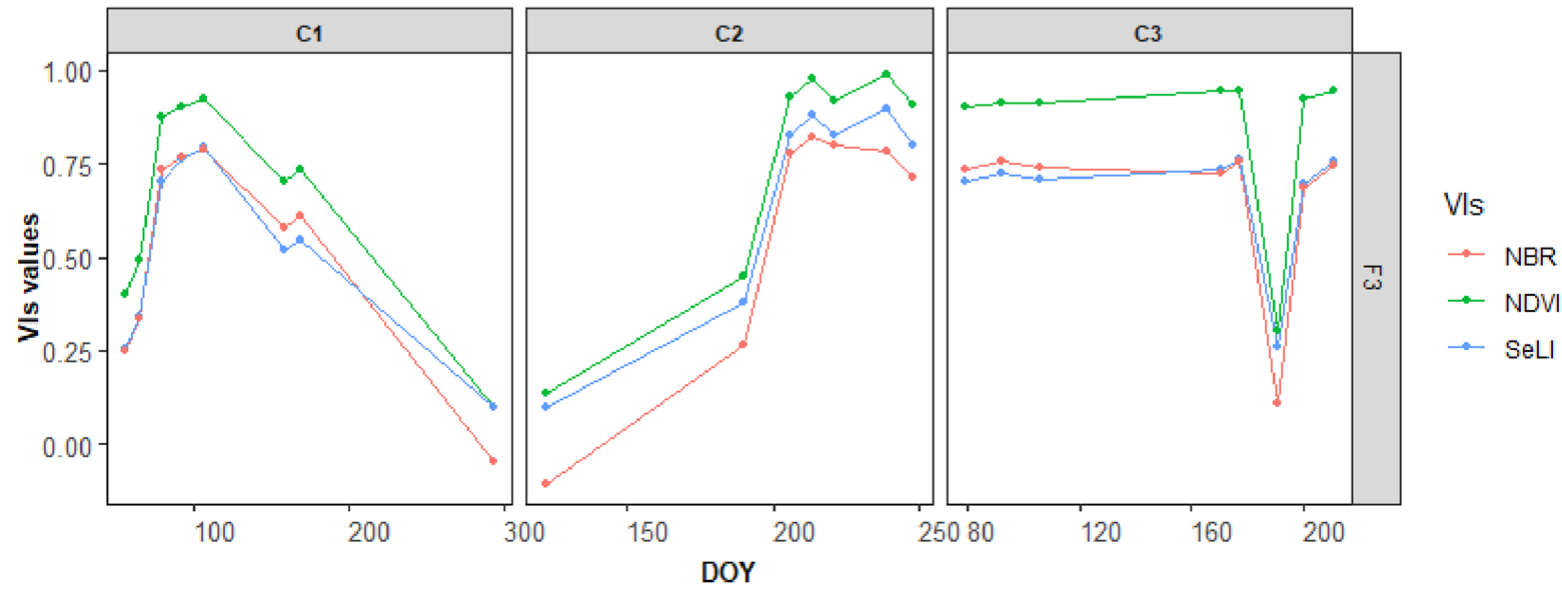

Figure A4. Multitemporal profile of VIs (NBR, NDVI, and SeLI) for the two-year ground-LAI sampling campaign. 

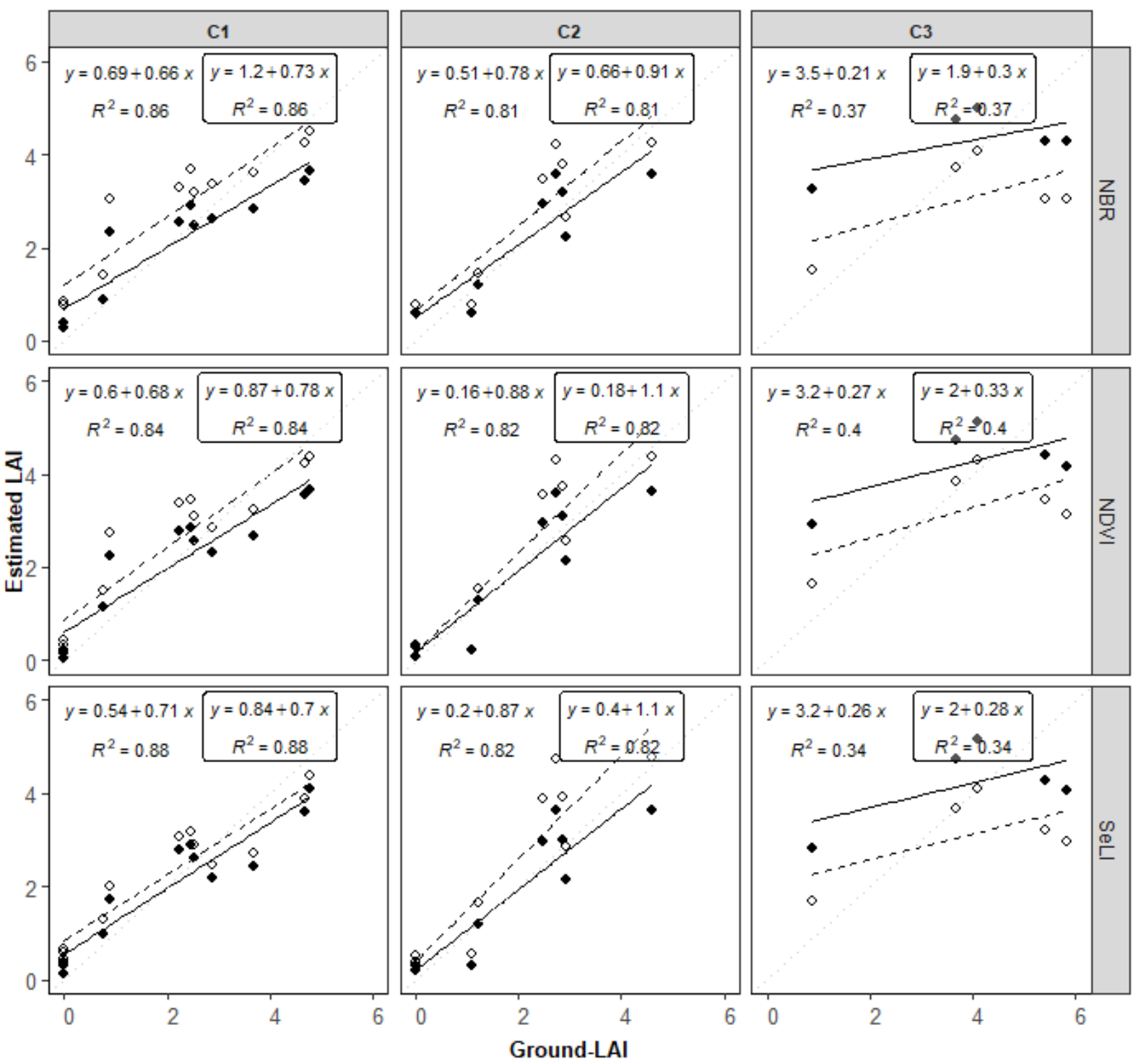

Figure A5. Results per crop (C1, C2, and C3) of linear regression analysis between measured ground-LAI and LAI predicted from NDVI, SeLI, and NBR by the mixed-crop (MC) LM (dashed line on black dots and equation in the box) and the crop-specific (CS) LM (continuous line on black dots).

\section{References}

1. Peng, Y.; Zhu, T.; Li, Y.; Dai, C.; Fang, S.; Gong, Y.; Wu, X.; Zhu, R.; Liu, K. Remote prediction of yield based on LAI estimation in oilseed rape under different planting methods and nitrogen fertilizer applications. Agric. For. Meteorol. 2019, $271,116-125$. [CrossRef]

2. Watson, D.J.; Watson, M.A. Comparative Physiological Studies on the Growth of Field Crops. Ann. Appl. Biol. 1947, 40, 1-37. [CrossRef]

3. Chen, J.M.; Black, T.A. Measuring leaf area index on plant canopies with brach arquitecture. Agric. For. Meteorol. 1991, 57, 1-12. [CrossRef]

4. Campos-Taberner, M.; García-Haro, F.J.; Camps-Valls, G.; Grau-Muedra, G.; Nutini, F.; Crema, A.; Boschetti, M. Multitemporal and multiresolution leaf area index retrieval for operational local rice crop monitoring. Remote Sens. Environ. 2016, 187, 102-118. [CrossRef]

5. Fassnacht, K.S.; Gower, S.T.; Norman, J.M.; McMurtric, R.E. A comparison of optical and direct methods for estimating foliage surface area index in forests. Agric. For. Meteorol. 1994, 71, 183-207. [CrossRef]

6. Jégo, G.; Pattey, E.; Liu, J. Using Leaf Area Index, retrieved from optical imagery, in the STICS crop model for predicting yield and biomass of field crops. Field Crop. Res. 2012, 131, 63-74. [CrossRef]

7. Fang, H.; Liang, S.; Hoogenboom, G. Integration of MODIS LAI and vegetation index products with the CSM-CERES-Maize model for corn yield estimation. Int. J. Remote Sens. 2011, 32, 1039-1065. [CrossRef] 
8. Gilardelli, C.; Stella, T.; Confalonieri, R.; Ranghetti, L.; Campos-Taberner, M.; García-Haro, F.J.; Boschetti, M. Downscaling rice yield simulation at sub-field scale using remotely sensed LAI data. Eur. J. Agron. 2019, 103, 108-116. [CrossRef]

9. Boschetti, M.; Busetto, L.; Ranghetti, L.; García-Haro, F.J.; Campos-Taberner, M.; Confalonieri, R. Testing Multisensors time series on LAI estimates to monitor rice phenology: Preliminary results. In Proceedings of the International Geoscience Remote Sensing Symposium (IGARSS), Valencia, Spain, 30 June 2018; pp. 8221-8224.

10. Asner, G.; Scurlock, J.; Hicke, J. Global synthesis of leaf area index observations: Implications for ecological and remote sensing studies. Glob. Ecol. Biogeogr. 2003, 12, 191-205. [CrossRef]

11. Bréda, N.J.J. Leaf Area Index. In Encyclopedia of Ecology; Jørgensen, S.E., Fath, B.D., Eds.; Elsevier: Amsterdam, The Netherland, 2008; pp. 2148-2154. ISBN 9780080454054.

12. Fang, H.; Liang, S. Leaf Area Index Models. In Reference Module in Earth Systems and Environmental Sciences; Elsevier: Amsterdam, The Netherlands, 2014; pp. 46-56. ISBN 9780124095489.

13. Verrelst, J.; Rivera, J.P.; Veroustraete, F.; Muñoz-Marí, J.; Clevers, J.G.P.W.; Camps-Valls, G.; Moreno, J. Experimental Sentinel-2 LAI estimation using parametric, non-parametric and physical retrieval methods-A comparison. ISPRS J. Photogramm. Remote Sens. 2015, 108, 260-272. [CrossRef]

14. Fang, H.; Baret, F.; Plummer, S.; Schaepman-Strub, G. An Overview of Global Leaf Area Index (LAI): Methods, Products, Validation, and Applications. Rev. Geophys. 2019, 57, 739-799. [CrossRef]

15. Mananze, S.; Pôças, I.; Cunha, M. Retrieval of Maize Leaf Area Index Using Hyperspectral and Multispectral Data. Remote Sens. 2018, 10, 1942. [CrossRef]

16. Siegmann, B.; Jarmer, T. Comparison of different regression models and validation techniques for the assessment of wheat leaf area index from hyperspectral data. Int. J. Remote Sens. 2015, 36, 4519-4534. [CrossRef]

17. Dong, T.; Liu, J.; Shang, J.; Qian, B.; Ma, B.; Kovacs, J.M.; Walters, D.; Jiao, X.; Geng, X.; Shi, Y. Assessment of red-edge vegetation indices for crop leaf area index estimation. Remote Sens. Environ. 2019, 222, 133-143. [CrossRef]

18. Delegido, J.; Verrelst, J.; Meza, C.M.; Rivera, J.P.; Alonso, L.; Moreno, J. A red-edge spectral index for remote sensing estimation of green LAI over agroecosystems. Eur. J. Agron. 2013, 46, 42-52. [CrossRef]

19. Delegido, J.; Verrelst, J.; Alonso, L.; Moreno, J. Evaluation of sentinel-2 red-edge bands for empirical estimation of green LAI and chlorophyll content. Sensors 2011, 11, 7063-7081. [CrossRef] [PubMed]

20. Nguy-Robertson, A.L.; Peng, Y.; Gitelson, A.A.; Arkebauer, T.J.; Pimstein, A.; Herrmann, I.; Karnieli, A.; Rundquist, D.C.; Bonfil, D.J. Estimating green LAI in four crops: Potential of determining optimal spectral bands for a universal algorithm. Agric. For. Meteorol. 2014, 192-193, 140-148. [CrossRef]

21. Kross, A.; McNairn, H.; Lapen, D.; Sunohara, M.; Champagne, C. Assessment of RapidEye vegetation indices for estimation of leaf area index and biomass in corn and soybean crops. Int. J. Appl. Earth Obs. Geoinf. 2015, 34, 235-248. [CrossRef]

22. Clevers, J.G.P.W.; Kooistra, L.; van den Brande, M.M. Using Sentinel-2 data for retrieving LAI and leaf and canopy chlorophyll content of a potato crop. Remote Sens. 2017, 9, 405. [CrossRef]

23. Herrmann, I.; Karnieli, A.; Bonfil, D.J.; Cohen, Y.; Alchanatis, V. SWIR-based spectral indices for assessing nitrogen content in potato fields. Int. J. Remote Sens. 2010, 31, 5127-5143. [CrossRef]

24. Amin, E.; Verrelst, J.; Rivera-Caicedo, J.P.; Pipia, L.; Ruiz-Verdú, A.; Moreno, J. Prototyping Sentinel-2 green LAI and brown LAI products for cropland monitoring. Remote Sens. Environ. 2020, 255, 112168. [CrossRef]

25. Mao, H.; Meng, J.; Ji, F.; Zhang, Q.; Fang, H. Comparison of Machine Learning Regression Algorithms for Cotton Leaf Area Index Retrieval Using Sentinel-2 Spectral Bands. Appl. Sci. 2019, 9, 1459. [CrossRef]

26. Upreti, D.; Huang, W.; Kong, W.; Pascucci, S.; Pignatti, S.; Zhou, X.; Ye, H.; Casa, R. A comparison of hybrid machine learning algorithms for the retrieval of wheat biophysical variables from sentinel-2. Remote Sens. 2019, 11, 481. [CrossRef]

27. Gonsamo, A.; Chen, J.M. Continuous observation of leaf area index at Fluxnet-Canada sites. Agric. For. Meteorol. 2014, 189, 168-174. [CrossRef]

28. Yan, K.; Park, T.; Chen, C.; Xu, B.; Song, W.; Yang, B.; Zeng, Y.; Liu, Z.; Yan, G.; Knyazikhin, Y.; et al. Generating global products of LAI and FPAR from SNPP-VIIRS data: Theoretical background and implementation. IEEE Trans. Geosci. Remote Sens. 2018, 56, 2119-2137. [CrossRef]

29. García-Haro, F.J.; Campos-Taberner, M.; Muñoz-Marí, J.; Laparra, V.; Camacho, F.; Sánchez-Zapero, J.; Camps-Valls, G. Derivation of global vegetation biophysical parameters from EUMETSAT Polar System. ISPRS J. Photogramm. Remote Sens. 2018, 139, 57-74. [CrossRef]

30. Baret, F.; Hagolle, O.; Geiger, B.; Bicheron, P.; Miras, B.; Huc, M.; Berthelot, B.; Niño, F.; Weiss, M.; Samain, O.; et al. LAI, fAPAR and fCover CYCLOPES global products derived from VEGETATION Part 1: Principles of the algorithm. Remote Sens. Environ. 2007, 110, 275-286. [CrossRef]

31. Gomarasca, M.A.; Tornato, A.; Spizzichino, D.; Valentini, E.; Taramelli, A.; Satalino, G.; Vincini, M.; Boschetti, M.; Colombo, R.; Rossi, L.; et al. Sentinel for Applications in Agriculture. ISPRS Int. Arch. Photogramm. Remote Sens. Spat. Inf. Sci. 2019, XLII-3/W6, 91-98. [CrossRef]

32. Morisette, J.T.; Baret, F.; Privette, J.L.; Myneni, R.B.; Nickeson, J.E.; Garrigues, S.; Shabanov, N.V.; Weiss, M.; Fernandes, R.A.; Leblanc, S.G.; et al. Validation of global moderate-resolution LAI products: A framework proposed within the CEOS land product validation subgroup. IEEE Trans. Geosci. Remote Sens. 2006, 44, 1804-1814. [CrossRef] 
33. Baret, F.; Weiss, M.; Allard, D.; Garrigues, S.; Leroy, M.; Jeanjean, H.; Fernandes, R.; Myneni, R.B.; Privette, J.; Morisette, J.; et al. VALERI: A network of sites and a methodology for the validation of medium spatial resolution land satellite products. Remote Sens. Environ. 2005, 76, 36-39.

34. Pasqualotto, N.; Delegido, J.; Van Wittenberghe, S.; Rinaldi, M.; Moreno, J. Multi-crop green LAI estimation with a new simple sentinel-2 LAI index (SeLI). Sensors 2019, 19, 904. [CrossRef] [PubMed]

35. Grubbs, F.E. Procedures for Detecting Outlying Observations in Samples. Technometrics 1969, 11, 1-21. [CrossRef]

36. R Core Development Team. R: A Language and Environment for Statistical Computing; R Foundation for Statistical Computing: Vienna, Austria, 2008; Volume 2.6.2.

37. Lancashire, P.D.; Bleiholder, H.; Boom, T.V.D.; Langelüddeke, P.; Stauss, R.; Weber, E.; Witzenberger, A. A uniform decimal code for growth stages of crops and weeds. Ann. Appl. Biol. 1991, 119, 561-601. [CrossRef]

38. Drusch, M.; Del Bello, U.; Carlier, S.; Colin, O.; Fernandez, V.; Gascon, F.; Hoersch, B.; Isola, C.; Laberinti, P.; Martimort, P.; et al. Sentinel-2: ESA's Optical High-Resolution Mission for GMES Operational Services. Remote Sens. Environ. 2012, 120, 25-36. [CrossRef]

39. Gascon, F.; Thépaut, O.; Jung, M.; Francesconi, B.; Louis, J.; Lonjou, V.; Lafrance, B.; Massera, S.; Gaudel-Vacaresse, A.; Languille, F.; et al. Copernicus Sentinel-2A Calibration and Products Validation Status. Remote Sens. 2017, 8, 584. [CrossRef]

40. Lonjou, V.; Desjardins, C.; Hagolle, O.; Petrucci, B.; Tremas, T.; Dejus, M.; Makarau, A.; Auer, S. MACCS-ATCOR joint algorithm (MAJA). Remote Sens. Clouds Atmos. XXI 2016, 10001, 1000107. [CrossRef]

41. Hijmans, R.J.; Etten, J.V.; Sumner, M.; Cheng, J.; Bevan, A.; Bivand, R.; Busetto, L.; Canty, M.; Forrest, D.; Golicher, D.; et al. Package 'raster' R topics documented. $R$ Packag. 2019, 508.

42. Nguy-Robertson, A.; Gitelson, A.A.; Peng, Y.; Viña, A.; Arkebauer, T.; Rundquist, D. Green leaf area index estimation in maize and soybean: Combining vegetation indices to achieve maximal sensitivity. Agron. J. 2012, 104, 1336-1347. [CrossRef]

43. Rouse, J.W.; Hass, R.H.; Schell, J.A.; Deering, D.W. Monitoring vegetation systems in the great plains with ERTS. Third Earth Resour. Technol. Satell. ERTS Symp. 1973, 1, 309-317.

44. Key, C.H.; Benson, N.C. Measuring and remote sensing of burn severity: The CBI and NBR. In Proceedings of the Joint Fire Science Conference and Workshop; Neuenschwander, L.F., Ryan, K.C., Eds.; University of Idaho: Moscow, ID, USA; International Association of Wildland Fire: Missoula, MT, USA, 1999; Volume II, p. 284.

45. Xie, Q.; Dash, J.; Huang, W.; Peng, D.; Qin, Q.; Mortimer, H.; Casa, R.; Pignatti, S.; Laneve, G.; Pascucci, S.; et al. Vegetation Indices Combining the Red and Red-Edge Spectral Information for Leaf Area Index Retrieval. IEEE J. Sel. Top. Appl. Earth Obs. Remote Sens. 2018, 11, 1482-1492. [CrossRef]

46. Ritz, C.; Spiess, A.N. qpcR: An R package for sigmoidal model selection in quantitative real-time polymerase chain reaction analysis. Bioinformatics 2008, 24, 1549-1551. [CrossRef]

47. Ritz, C.; Streibig, J.C. Bioassay analysis using R. J. Stat. Softw. 2005, 12, 1-22. [CrossRef]

48. Ritz, C.; Baty, F.; Streibig, J.C.; Gerhard, D. Dose-Response Analysis Using R Christian. PLoS ONE 2015, 10, e0146021. [CrossRef]

49. Rasmussen, C.E.; Williams, C.K.I. Gaussian Processes for Machine Learning; The MIT Press: New York, NY, USA, 2006.

50. Breiman, L. Bagging predictions. Mach. Learn. 1996, 24, 123-140. [CrossRef]

51. Friedman, J.; Tibshirani, R.; Hastie, T. Additive logistic regression: A statistical view of boosting (with discussion and a rejoinder by the authors). Ann. Stat. 2000, 28, 337-407. [CrossRef]

52. Caicedo, J.P.; Verrelst, J.; Munoz-Mari, J.; Moreno, J.; Camps-Valls, G. Toward a semiautomatic machine learning retrieval of biophysical parameters. IEEE J. Sel. Top. Appl. Earth Obs. Remote Sens. 2014, 7, 1249-1259. [CrossRef]

53. Verrelst, J.; Rivera, J.P.; Alonso, L.; Moreno, J. ARTMO: An Automated Radiative Transfer Models Operator toolbox for automated retrieval of biophysical parameters through model inversion. In Proceedings of the EARSeL 7th SIG-Imaging Spectroscopy Workshop, Edinburgh, UK, 11-13 April 2011; pp. 11-13.

54. Kohavi, R. A Study of Cross-Validation and Bootstrap for Accuracy Estimation and Model Selection. In Proceedings of the 14th International Joint Conference on Artificial Intelligence, Monreal, QC, Canada, 20-25 August 1995; Volume 118, pp. $20-25$.

55. Verrelst, J.; Rivera, J.; Gitelson, A.A.; Delegido, J.; Moreno, J.; Camps-Valls, G. Spectral band selection for vegetation properties retrieval using Gaussian processes regression. Int. J. Appl. Earth Obs. Geoinf. 2016, 52, 554-567. [CrossRef]

56. Belda, S.; Pipia, L.; Morcillo-Pallarés, P.; Rivera-Caicedo, J.P.; Amin, E.; De Grave, C.; Verrelst, J. DATimeS: A machine learning time series GUI toolbox for gap-filling and vegetation phenology trends detection. Environ. Model. Softw. 2020, 127, 104666. [CrossRef]

57. Kira, O.; Nguy-Robertson, A.L.; Arkebauer, T.J.; Linker, R.; Gitelson, A.A. Informative spectral bands for remote green LAI estimation in C3 and C4 crops. Agric. For. Meteorol. 2016, 218-219, 243-249. [CrossRef]

58. Revill, A.; Florence, A.; MacArthur, A.; Hoad, S.P.; Rees, R.M.; Williams, M. The value of Sentinel-2 spectral bands for the assessment of winter wheat growth and development. Remote Sens. 2019, 11, 2050. [CrossRef]

59. Facchi, A.; Baroni, G.; Boschetti, M.; Gandolfi, C. Comparing Opticaland Direct Methods for Leafarea Index Determination in a Maize Crop. J. Agric. Eng. 2010, 41, 33. [CrossRef]

60. Verger, A.; Martínez, B.; Camacho-de Coca, F.; García-Haro, F.J. Accuracy assessment of fraction of vegetation cover and leaf area index estimates from pragmatic methods in a cropland area. Int. J. Remote Sens. 2009, 30, 2685-2704. [CrossRef]

61. Casa, R.; Upreti, D.; Pelosi, F. Measurement and estimation of leaf area index (LAI) using commercial instruments and smartphonebased systems. IOP Conf. Ser. Earth Environ. Sci. 2019, 275, 012006. [CrossRef] 
62. Leblanc, S.G.; Chen, J.M. A practical scheme for correcting multiple scattering effects on optical LAI measurements. Agric. For. Meteorol. 2001, 110, 125-139. [CrossRef]

63. Viña, A.; Gitelson, A.A.; Nguy-Robertson, A.L.; Peng, Y. Comparison of different vegetation indices for the remote assessment of green leaf area index of crops. Remote Sens. Environ. 2011, 115, 3468-3478. [CrossRef]

64. Herrmann, I.; Pimstein, A.; Karnieli, A.; Cohen, Y.; Alchanatis, V.; Bonfil, D.J. LAI assessment of wheat and potato crops by $\mathrm{VEN} \mu \mathrm{S}$ and Sentinel-2 bands. Remote Sens. Environ. 2011, 115, 2141-2151. [CrossRef]

65. Taramelli, A.; Tornato, A.; Magliozzi, M.L.; Mariani, S.; Valentini, E.; Zavagli, M.; Costantini, M.; Nieke, J.; Adams, J.; Rast, M. An Interaction Methodology to Collect and Assess User-Driven Requirements to Define Potential Opportunities of Future Hyperspectral Imaging Sentinel Mission. Remote Sens. 2020, 12, 1286. [CrossRef]

66. Liang, L.; Di, L.; Zhang, L.; Deng, M.; Qin, Z.; Zhao, S.; Lin, H. Estimation of crop LAI using hyperspectral vegetation indices and a hybrid inversion method. Remote Sens. Environ. 2015, 165, 123-134. [CrossRef]

67. Delloye, C.; Weiss, M.; Defourny, P. Retrieval of the canopy chlorophyll content from Sentinel-2 spectral bands to estimate nitrogen uptake in intensive winter wheat cropping systems. Remote Sens. Environ. 2018, 216, 245-261. [CrossRef]

68. Asrar, G.; Fuchs, M.; Kanemasu, E.T.; Hatfield, J.L. Estimating Absorbed Photosynthetic Radiation and Leaf Area Index from Spectral Reflectance in Wheat. Agron. J. 1984, 76, 300. [CrossRef]

69. Sellers, P.J. Canopy reflectance, photosynthesis and transpiration. Int. J. Remote Sens. 1985, 68, 1335-1372. [CrossRef] 